\title{
An overview of mesenchymal stem cells and their potential therapeutic benefits in cancer therapy (Review)
}

\author{
SHERN KWOK LIM and BOON YIN KHOO \\ Institute for Research in Molecular Medicine, Universiti Sains Malaysia, 11800 Penang, Malaysia
}

Received March 25, 2021; Accepted July 27, 2021

DOI: 10.3892/ol.2021.13046

\begin{abstract}
There has been increased interest in using stem cells for regenerative medicine and cancer therapy in the past decade. Mesenchymal stem cells (MSCs) are among the most studied stem cells due to their unique characteristics, such as self-renewal and developmental potency to differentiate into numerous cell types. MSC use has fewer ethical challenges compared with other types of stem cells. Although a number of studies have reported the beneficial effects of MSC-based therapies in treating various diseases, their contribution to cancer therapy remains controversial. The behaviour of MSCs is determined by the interaction between intrinsic transcriptional genes and extrinsic environmental factors. Numerous studies continue to emerge, as there is no denying the potential of MSCs to treat a wide variety of human afflictions. Therefore, the present review article provided an overview of MSCs and their differences compared with embryonic stem cells, and described the molecular mechanisms involved in maintaining their stemness. In addition, the article examined the therapeutic application of stem cells in the field of cancer. The present article also discussed the current divergent roles of MSCs in cancer therapy and the future potential in this field.
\end{abstract}

\section{Contents}

1. Introduction

2. Genetic regulators for multipotency of mesenchymal stem cells (MSCs)

3. Extrinsic regulators for multipotency of MSCs

4. Clinical applications of MSCs

5. Therapeutic potential of MSCs

6. MSCs in cancer therapy

Correspondence to: Dr Boon Yin Khoo, Institute for Research in Molecular Medicine, Universiti Sains Malaysia, H53 Jalan Inovasi, 11800 Penang, Malaysia

E-mail: boonyin@usm.my

Key words: mesenchymal stem cells, cell-based therapies, therapeutic stem cells, cancer therapy
7. Potential strategy in utilizing MSCs for cancer therapy

8. Concluding remarks and future perspectives

\section{Introduction}

The human body contains numerous different cell types, which make up tissues and organs with specific functions that play a role in ensuring sustainability. It was discovered long ago that differentiated cells in some tissues, e.g., skin, intestinal epithelium and blood, have a short lifecycle and are incapable of self-renewal (1). Stem cells are able to self-renew and possess developmental potency to differentiate into numerous cell types of an organism. This finding led to the concept of stem cells as small unspecialized cells in the human body devoid of a number of phenotypic traits commonly found in cells from adult tissues for maintaining static and transient cell types (2). Potency with each differentiation step classifies stem cells into totipotent, pluripotent, multipotent, oligopotent and unipotent stem cells (3). As potency decreases, the possible cell types that stem cells can differentiate into also decrease accordingly.

Stem cells are generally categorized into two main groups: embryonic and nonembryonic (somatic stem cells). Embryonic stem cells (ESCs) are pluripotent, while somatic stem cells, e.g., mesenchymal stem cells (MSCs), are multipotent $(4,5)$. ESCs were first isolated from mouse embryos (6), while MSCs were discovered in monolayer cultures of guinea pig bone marrow (7). Following their initial discovery, human stem cells were isolated and cultured, whereby ESCs were derived from human blastocysts (8) while MSCs were derived from human bone marrow (9). These achievements in isolating and culturing human stem cells opened new possibilities to better understand the basic molecular mechanisms behind human development and differentiation, leading to potential new treatments for various diseases. While the potential benefits of research on human ESCs are immense, there is a major ethical issue to address, e.g., the derivation of human ESCs results in the destruction of an embryo. In addition, reliance on human embryos may also lead to the commodification and exploitation of women (10-12). Indeed, the potential exploitation of women involving the donation or sales of oocytes or embryos for research and the purposeful creation of embryos for research remain huge ethical issues that need to be addressed. This ethical dilemma negatively impacts the benefit-to-risk ratio, and hence, research has moved towards 
somatic stem cells instead. Despite the focus on ESCs, MSCs have been extensively researched in clinical settings during the past decade (13-24) because MSCs can be easily obtained and cultured for clinical use from multiple tissue sources that are easily accessible using minimally intrusive methods, reducing the ethical dilemmas surrounding human stem cell research (25). Additionally, MSCs can differentiate into a variety of cell types that confer pleiotropic effects when used for therapeutic purposes (26). MSCs were initially discovered in bone marrow, and studies have reported that these stem cells can also be found in other postnatal organs and tissues, e.g., brain, kidney, liver, lung, spleen, adipose tissue, muscle, hair follicles, teeth, placenta, and umbilical cord $(27,28)$. The International Society for Cellular Therapy (ISCT) defines three minimal criteria that need to be fulfilled for MSCs to overcome the issue of different characteristics due to isolation from different tissue types (29):

1. MSCs must adhere to plastic surfaces when cultured in vitro.

2. The surface anti-genes CD73, CD90, and CD105 must be expressed by MSCs, while CD34, CD45, CD14 or CD11b, CD79 $\alpha$ or CD19, and HLA-DR surface molecules should be absent.

3. MSCs must be able to differentiate into different mesodermal cell types, e.g., adipocytes, chondrocytes, and osteoblasts, when cultured in vitro under certain conditions.

In addition to these criteria, the ISCT recommended three additional conditions in 2019 to further clarify the nomenclature of MSCs to avoid confusion between mesenchymal stem cells and mesenchymal stromal cells (30). The tissue-source origin of MSCs should be documented to highlight tissue-specific properties, e.g., phenotypic, functional and secretome behaviour. Comprehensive in vitro and in vivo data demonstrate the stemness of MSCs associated with a robust matrix of functional assays that test the functionality of MSCs in vitro and in vivo based on their proposed utility.

Previous studies have reported that MSCs are multipotent and capable of differentiating into cells of mesodermal, ectodermal, and endodermal lineages (29,31-33). This plasticity of MSCs and their self-renewal capacity make these cells promising therapeutic targets for various diseases, including cancer treatment and tissue regeneration. MSCs undeniably offer immense potential in the field of medicine; however, the cells also present potential danger due to their ability to differentiate into tumour-associated fibroblasts (34-36), which support tumour growth through their secretome $(37,38)$ and resistance to apoptosis (39). Due to their conflicting role in cancer progression and regression, efforts to utilize MSCs in anticancer therapies have been unsuccessful. Therefore, it is important to understand the underlying molecular mechanisms of MSCs to fully utilize their therapeutic potential.

\section{Genetic regulators for multipotency of MSCs}

Significant advancements in DNA sequencing, computational biology, and bioinformatics have been made to identify transcriptional processes associated with the multipotency of MSCs. Based on previous studies, cyclin L2 (CCNL2), stromal cell-derived factor 1 (CXCL12), podocalyxin-like protein (PODXL), and ubiquitin carboxyl-terminal hydrolase 1 (USP1) were identified as four genes responsible for maintaining multipotency, chromosomal integrity, and MSC functions (40-42). CCNL2 was reported to inhibit proliferation and cell specialization while promoting apoptosis upon upregulation in mouse embryonic carcinoma P19 cells. In the same study, CCNL2-overexpressing P19 cells had a remarkably decreased S phase and reduced expression levels of myocardial cell differentiation-related genes, e.g., cardiac actin, GATA binding protein 4 (GATA4), myocyte-specific enhancer factor 2C (Mef2C), homeobox protein Nkx-2.5 (Nkx2.5), and B-type natriuretic peptide (BNP) (43). On the other hand, CXCL12 is a chemokine protein that induces the migration of stem cells. It functions by binding to CXC chemokine receptor (CXCR) 4, CXCR7 and atypical chemokine receptor 3 (ACKR3) $(44,45)$. CXCL12 has been reported to be responsible for cell survival, growth and migration during tissue/organ development (46). While the exact mechanism by which CXCL12 helps maintain the stemness of MSCs has not been elucidated, there are numerous reports on its function in other stem cells. The CXCL12-CXCR4 axis was found to be responsible for cell migration, while the CXCL12-CXCR7 axis promotes cell adhesion in cardiac stem cells. Similar findings also reported the importance of CXCL12-mediated CXCR4 signalling in controlling the position of haematopoietic stem cells in bone marrow niches, which contain limiting lymphoid-instructive cytokines that are responsible for the multipotency of HSCs and their maintenance (47). A study confirmed that CXCL12-mediated CXCR4 signalling promotes the proliferation, survival, and migration of mesenchymal stromal cells in vitro (48). It is also likely that CXCL12 acts through a similar mechanism to help MSCs maintain their stemness.

PODXL is mainly involved in cell proliferation and oncosphere formation (49). However, the exact mechanism of action in maintaining the multipotency of MSCs is currently not well understood. A previous study reported that higher expression of PODXL and CD49f in MSCs increased the clonogenic potential, viability, and differentiation capabilities of MSCs (41). There may also be an interaction between PODXL and CCNL2, whereby both genes work together to help maintain the multipotency of MSCs. Nonetheless, further studies are warranted before this phenomenon can reach a suitable conclusion. USP1 encodes a deubiquitinating enzyme. USP1 was also found to stabilize inhibitors of DNA binding, which play a role in inhibiting cell specialization while enhancing proliferation (42). As interest in using MSCs for therapeutic purposes grows. Moreover, previous studies have reported other genes and novel mechanisms by which the stemness of MSCs is maintained (50-52). The therapeutic potential of MSCs mostly stems from their ability to self-renew and differentiate. The exact mechanism by which MSC multiplicity is maintained remains ambiguous, and likely, these genes work together in a balancing act to ensure the renewal and stemness of MSCs. Therefore, a clearer understanding should be made available to ensure the safety and efficacy of treatments using MSCs. After all, both the potential therapeutic benefits 
and danger come from the self-renewal ability, migration, and stemness of MSCs.

\section{Extrinsic regulators for multipotency of MSCs}

The niche microenvironment strongly influences the behaviour of stem cells. As mentioned, CXCL12 maintains multipotency by directing MSCs to specific niches, where secreted factors influence their self-renewal and stemness (53). This phenomenon indicates that the behaviour of MSCs is determined by the interaction between intrinsic transcriptional genes and extrinsic factors of the environment. It has been established that the protein kinase B (Akt) and extracellular-signal-regulated kinase (Erk) signalling pathways control both stem cell proliferation and survival, while the Wnt, Notch, and Sonic hedgehog (Shh) signalling pathways regulate stem cell renewal and differentiation (54-57). A study also proposed two novel mechanisms that help to maintain the stemness of MSCs via the scrapie responsive gene 1 (SCRG1)/bone marrow stromal cell anti-gene 1 (BST1) ligand-receptor combination and cell-cell adhesion through $\mathrm{N}$-cadherin (52). An improved understanding of the underlying mechanism involved in stem cell renewal and differentiation is important because the original abilities are lost at a high rate during long-term in vitro culture $(58,59)$. Therefore, current work should develop novel techniques to ensure that MSCs maintain their multipotency despite long-term in vitro culture. This would, in turn, maintain the potential of MSCs to be used in regenerative medicine and cell therapy.

Epigenetic factors influence the differential gene expression in MSCs that causes cell differentiation. Hence, the DNA sequences of MSCs and their specialized cell types are similar, with almost no difference. Commonly studied epigenetic modifications include DNA methylation and histone modification, e.g., methylation, acetylation, ubiquitylation, and microRNAs. Once epigenetic modifications occur, gene expression can be influenced by changing the availability of gene promoters, thus affecting the recruitment of supplementary chromatin-modifying enzymes or transcriptional regulators that drive stem cell differentiation (60). For example, runt-related transcription factor 2 (Runx2) regulates most osteoblast-specific genes by working together with numerous coactivators and corepressors that alter the binding of Runx2 to the osteocalcin promoter. This binding modification occurs through DNA methylation and acetylation of histones $\mathrm{H} 3$ and H4 (61). Additionally, Runx 2 changes the expression of its target in response to other signals, e.g., transforming growth factor-beta (TGF- $\beta$ ), bone morphogenetic protein (BMP) and Wnt signalling pathways (60), is responsible for the osteogenic lineage. MSCs can also undergo adipogenic differentiation, whereby hypomethylation of the genes encoding peroxisome proliferator-activated receptors gamma-2 (PPAR $\gamma 2$ ), fatty acid-binding protein 4 (FABP4), leptin (lep) and lipoprotein lipase $(1 \mathrm{pl})$ was reported to be responsible for these mechanisms $(61,62)$.

In addition to secreted factors, the cyclic tensile strain that can alter cell behaviour should be considered another microenvironmental factor. MSCs have been observed to lose multipotency and spontaneously differentiate after prolonged passaging in vitro $(25,63)$. Therefore, in vitro culture conditions must be optimized to maintain the multipotency of MSCs for their therapeutic potential in clinical settings. A study found that low actomyosin contractility induced by restricting the cells to small islands during initial culture is necessary to ensure the stemness of MSCs (64). A disparity in differential gene expression when MSCs are cultured in 2D and 3D culture systems is likely due to the interaction between the cells in an intricate 3D structure compared to that in a monolayer 2D culture (65). Recent studies have also found that cyclic tensile strain promotes bone marrow-derived MSCs (BMSCs) to differentiate into cardiomyocyte-like cells (66) and adipose stem cells to differentiate into the osteogenic lineage (67). However, the regulatory pathways and epigenetic factors that might be involved seem to depend on the source of MSCs and the desired cell lineage.

\section{Clinical applications of MSCs}

MSCs have been the subject of clinical trials for the past decade, but the outcomes have fallen short of expectations despite promising data in animal models. Studies continue to emerge, as there is no denying the potential of MSCs to treat a wide variety of human afflictions, e.g., neurodegeneration, ageing, blindness, diabetes, and cancers (1). It is crucial to realistically assess the time and effort required to establish new clinical settings for numerous therapeutic applications. The same concern regarding the efficacy and safety of treatment must also always be at the forefront when considering the usage of MSCs, as there are crucial biological and pharmacological discrepancies in preclinical and clinical studies. The first clinical trial using MSCs as a therapeutic agent was in 1995 (68). Since then, MSCs have become the most widely clinically studied cell-based therapy worldwide (69). MSCs are currently classified as advanced therapy medicinal products (ATMPs), which follow the Good Manufacturing Practices (GMP) guidelines of the Food and Drug Administration (FDA) and the European Medicines Agency (EMA) to authenticate and ensure the quality of cells before their administration to patients (70). This compliance with GMP includes the sources of MSCs, reagents, equipment, packaging materials, procedures, laboratory staff, environment, and final cellular medicine (71).

It is of the utmost importance that GMP conditions are maintained according to the international and national medicinal governing framework. This act ensures the quality of the administered MSCs and prevents possible contamination issues that may cause adverse reactions in patients and even death. However, there is currently a lack of unified and standard criteria for manufacturing MSCs as a therapeutic agent due to some differences over specific issues depending on the USA, Europe, Canada, Singapore, Japan and so forth. Despite this challenge, consistent physical and microbiological testing of the MSC production laboratory and cleanrooms to ensure the sterility of the production process is also warranted (72). This act fulfils the requirement of International Standard Organization (ISO) standard 14644.

Currently, 1,088 studies registered as clinical trials list MSCs as a clinical intervention. The majority of these trials, whether ongoing or completed, are phase 1 or 2 studies that evaluate the safety and efficacy of MSCs in humans. Despite 
the most promising results, MSC-based therapies still have significant limitations due to the nature of the stem cells, e.g., MSCs markedly differ in gene expression profile, cell differentiation ability, growth rate, and therapeutic capacity, depending on their tissue source (63). Therefore, it may be vital to isolate and culture homogenous populations of MSCs to improve the efficacy and safety of the treatment. The method of transplanting MSCs isolated and grown in large batches from unrelated donor tissues is known as allogeneic transplantation; in contrast to autologous therapy, MSCs are extracted and grown from treated patients. The benefits of allogeneic transplantation include:

1. Efficiency, such as the isolation, expansion, and validation of MSCs from the patient, is not required.

2. The therapeutic functions of allogenic MSCs remain the same, unlike autologous MSCs, which have been reported to have impaired functions when isolated from elderly individuals $(73,74)$.

3. A well-established stock of MSCs following strict GMP requirements reduces the variability of donors and improves the success rate of the treatment.

Allogeneic transplantation, however, may induce an immunogenic response (75), especially when administered repeatedly at the same site (76). This phenomenon makes allogeneic therapy less desirable, especially when it needs to be administered for an extended period. At the same time, in vitro studies have reported on the hypoimmunogenic properties (immune-privileged) of MSCs, while the findings of in vivo studies were less conclusive (77). It was theorized that MSCs lose their hypoimmunogenic properties upon differentiation, which triggers the immune response and rejection after implantation into the host $(77,78)$. A study also reported that different transplantation routes and microenvironments could influence the immunogenicity of implanted MSCs (79). Because of such inconclusive in vivo results, a paper suggested the term immune evasive be used instead of immune-privileged to describe the immunogenicity of MSCs. It was also reported that while MSCs may not be truly immune-privileged, the rejection of allogeneic MSCs occurs at a slower rate than that of other cell types (80). This phenomenon means that future studies should also examine strategies to maintain or prolong the immunogenicity of allogeneic MSCs to maximize the therapeutic benefits.

In contrast, autologous transplantation, which triggers less risk of immunogenic response, is an alternative. Autologous MSCs are easily available without identifying a suitable donor (81). Autologous MSCs also overcome the limitation of long-term in vitro culture for allogeneic MSCs, leading to loss of multipotency, morphological changes, and an increased risk of malignancy $(25,74)$. Nonetheless, the challenge and reliance on autologous MSC transplantation mean that a well-optimized and established protocol for the isolation and ex vivo preparation of MSCs will be required. Such precise standardization may be difficult, as several exogenous factors greatly affect the biological properties of MSCs (70). Autologous MSCs may not be suitable for treating certain genetic diseases due to the mutations present in stem cells. Flaws in the genetic sequence hinder both the immunomodulatory function and regenerative traits of MSCs. For example, MSCs isolated from patients suffering from systemic lupus erythaematosus have a senescent phenotype with diminished capabilities to differentiate, migrate and regulate the immune system (79,82-84). Therefore, more preclinical and clinical studies are required to obtain more information related to the utility of MSCs as a therapeutic approach. Supplementary studies on the basic biology of MSC maintenance and the regulators of MSC differentiation would also provide a clearer picture of how to better administer MSCs as therapeutic agents in the future.

Most of the published clinical studies employing MSCs for diseases have specific treatments with positive outcomes. In neurology, ischaemic stroke patients treated with MSCs yielded positive results, whereby the patients showed significantly improved neurological and motor functions (85-88). Among all of the studies conducted, serious adverse events that were reported included transient ischaemic attack, seizure, asymptomatic subdural haematoma/hygroma, urinary tract infection, sepsis, pneumonia, hyperglycaemia, neutrophilia, shingles, ischaemic stroke, cellulitis, muscle cramps, fracture neck femur, and peripheral vascular disease (89). However, these side effects were attributed to the procedure rather than cell therapy. The study also reported promising results in the field of cardiology. Studies have shown that diseases, e.g., dilated cardiomyopathy and ischaemic or nonischaemic heart failure, have had clinical and pathophysiological improvements; no serious adverse effects were reported, demonstrating the treatment's safety profile (19,90-92). Patients suffering from cartilage lesions and/or osteoarthritis, especially in the knee, were reported to have a clinical improvement in pain, stiffness, and functionality when treated with MSCs. These results show the broad potential of MSCs for clinical usage with no serious adverse effects linked to cell therapy.

\section{Therapeutic potential of MSCs}

Interest in developing MSCs as therapeutic agents has not waned in the slightest, despite the obstacles faced, largely due to their immense therapeutic potential. In addition to being multipotent with self-renewing capabilities, MSCs also have the added benefits of migrating to the injury site and promoting tissue regeneration (26). This phenomenon means that MSCs can be a form of personalized therapy (when opting for autologous therapy) that is site-directed, promotes tissue restoration, and replaces damaged cells through differentiation. It is, therefore, unsurprising that scientists are so invested in advancing this field of research since the therapeutic agent reaches the targeted tissue for effective disease treatment. As MSCs have a natural tendency to be attracted towards damaged sites and the tumour microenvironment, the cells are a prime candidate for further investigation, as MSCs seem to be independent of the type of tumour, immunocompetence and delivery route (93).

Insight into the mechanism underlying the mobilization of MSCs to the injury site is still limited, but CXCL12-mediated CXCR4 signalling is most likely involved as a pathway that mediates cell migration (94). Secreted chemokines can mediate inflammation in the tumour microenvironment, and wounds are responsible for attracting MSCs (95). As the chemotactic properties of MSCs seem to be similar to those of other immune cells, the established model of leukocyte migration 
can be used as a template to study the factors involved in MSC migration (95). Other chemokine receptors that react to signals from the injury site or tumour microenvironment induce CCR1-2, CXCR1-2, CCR4, CXCR4-6, CCR7-10, and CX3R1 expression in MSCs (95). In addition, cell adhesion molecules expressed by MSCs, e.g., CD44, CD49d, CD54, CD102 and CD106, are thought to be involved in MSC migration to injury sites $(26,96)$.

A wide variety of trophic mediators and growth factors are secreted to initiate tissue regeneration once MSCs arrive at the injury site. The pleiotropic effects conferred by MSCs towards damaged tissues include anti-inflammation, immunomodulation, and enhanced cell survival and angiogenesis $(97,98)$. Among these therapeutic effects, anti-inflammation and immunomodulation are key elements that make MSCs an attractive target to study because the immune system plays an integral role in regulating tissue repair and regeneration through healing, scarring and fibrosis (99). The immunomodulatory process of MSCs occurs through the secretion of several soluble factors that interfere with the immune system, and the inflammation process takes place through cell-cell interactions $(100,101)$. The immunosuppressive effect of MSCs was enhanced by increasing the binding between MSCs and T-cells through intercellular adhesion molecule-1 (ICAM-1) and vascular cell adhesion molecule-1 (VCAM-1) (102). A similar phenomenon was reported when MSCs were shown to heighten the suppressive regulation of T-cells and macrophages regarding proinflammatory macrophages (103).

The flexibility of multipotent MSCs to differentiate into a wide variety of cells would then allow the cells to replace damaged or dead cells. However, reports on this mechanism are inconclusive, as the engraftment of MSCs is transient, and instead, MSCs secrete specific factors that grow and differentiate into local precursor cells (26). The potential of MSCs in tissue repair and regeneration is undeniable, regardless of the exact mechanisms.

\section{MSCs in cancer therapy}

Over the years, multiple reports have been published that strongly suggest the mechanism of action of MSCs. These actions are mainly attributed to the ability to migrate to the injury site (104-106), the paracrine effect of the secretome $(107,108)$, and the immunomodulatory ability $(109,110)$. The benefits of MSCs are enticing, and it is important to consider the potential side effects and major risk factors that are often associated with stem cell transplantation. There have been contradictory results in describing the anti- and pro-tumour effects of MSCs. As mentioned above, the therapeutic role of MSCs in cancer therapy is similar to that in other diseases; tumours secrete similar chemoattractants to damaged tissues, which initiate the migration of MSCs to the target site through the CXCL12-CXCR4 signalling pathway (111-114). MSCs have also been reported to interact with cancer cells, directly and indirectly, affecting tumour development (26). Moreover, MSCs secrete various cytokines and growth factors, which alter cellular activities, e.g., cell proliferation (cell cycle), angiogenesis, cell survival, and immunomodulation, to indirectly influence tumour growth. For example, BMSCs were described to enhance the proliferation of B16-LacZ cells and increase tumour size when both cell lines were coinjected into syngeneic mice via enhanced angiogenesis (115). In contrast, BMSCs were also reported to inhibit proliferation, migration, and invasion and induce cell cycle arrest, which led to apoptosis of human glioma U251 cells by downregulating the PI3K/Akt pathway (116).

Indeed, such paradoxical results are not uncommon, as divergent effects on cell growth, invasion, and migration have been reported when MSCs sourced from the human umbilical cord were cocultured with glioblastoma cancer stem cells, e.g., direct contact between both cell lines caused an inhibitory response (117). At the same time, the release of soluble factors triggered a stimulatory reaction (117). Similar opposing effects were observed during an in vivo study investigating whether coinjection and distant injection of MSCs with breast tumour 4T1 cells exerted different effects on tumour growth (118). Coinjection supported tumour growth, while in the distant injection model, it inhibited tumour growth by promoting host antitumour immunity (118). Likewise, MSCs derived from umbilical cord blood and adipose tissue also had divergent effects on the proliferation of glioblastoma multiforme. The former inhibited and promoted the proliferation process (119).

Several studies have found that upon being recruited to tumour sites, the multipotency of MSCs enables their self-differentiation into carcinoma-associated fibroblasts, which directly contribute to cancer progression (120-122). In addition, MSCs were reported to promote tumour growth and angiogenesis through the secretion of proangiogenic cytokines, e.g., interleukin (IL)-6, vascular endothelial growth factor (VEGF), and transforming growth factor- $\beta$ (TGF- $\beta$ ) (123-125) (Fig. 1). MSCs also enhanced the metastasis of human breast cancer cells by promoting de novo production of lysyl oxidase (LOX) by cancer cells (126). In addition, MSCs are able to modulate the production of regulatory T-cells and inhibit the activity of natural killer (NK) cells and cytotoxic $\mathrm{T}$ lymphocytes (CTLs), protecting breast cancer cells from the immune system (127). Similar immunosuppressive effects were observed when MSCs were reported to promote lung cancer metastasis (128). It was suggested that MSCs have the ability to form a cancer stem cell niche in vivo where tumour cells can preserve the potential to proliferate, thus sustaining the malignant process (129).

In contrast, MSCs increased the sensitivity of breast cancer cells to radiotherapy and impeded tumour progression by downregulating the signal transducer and activator of transcription 3 (Stat3) signalling pathway (130). Another study found that MSCs hampered hepatic cancer growth through the secretion of paracrine factors that lowered the insulin-like growth factor 1 receptor (IGF-1R), phosphatidylinositol 3-kinase (PI3K) and Akt signalling pathways (131). In addition, microRNA-4461 isolated from BMSCs was reported to inhibit tumour pathogenesis in colorectal cell lines and tissues by downregulating the expression of COPB2 (132). MSCs also inhibited vascular growth in glioma cells by downregulating the platelet-derived growth factor (PDGF)/PDGFR axis (133). Antiproliferative effects and apoptosis were observed when ovarian cancer cell lines were cocultured with conditioned media of MSCs derived from human bone marrow, adipose 


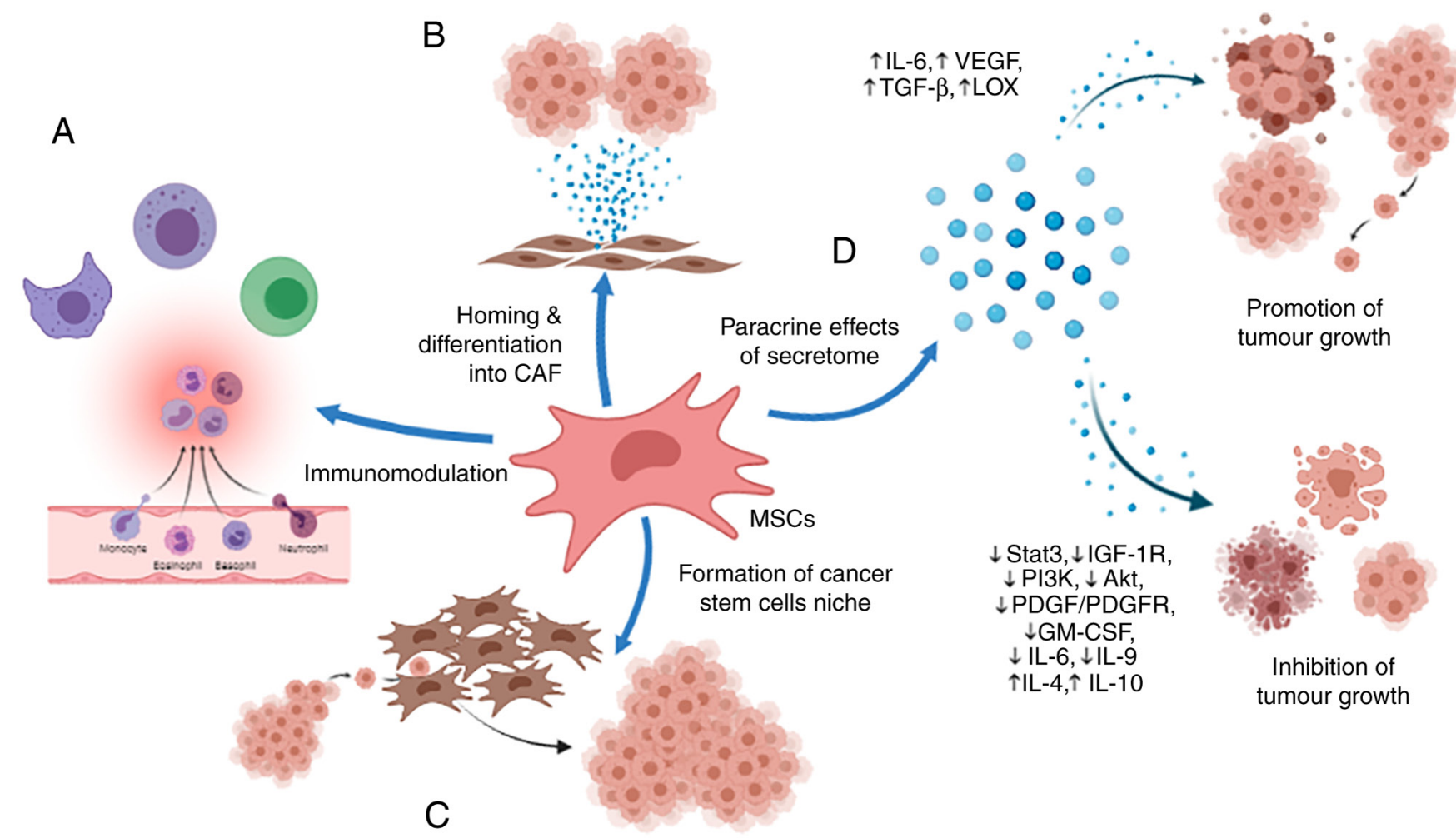

Figure 1. Summary of the mechanism of action of MSCs on the modulation of tumour cell growth. (A) MSCs regulate the immunomodulatory process by secreting several soluble factors that interfere with the immune system. MSCs also reveal their immunomodulatory potential through cell-cell interaction by activating monocytes, eosinophils, basophils and neutrophils. (B) MSCs are multipotent progenitors able to migrate, home and differentiate into CAFs. (C) MSCs have the ability to form a cancer stem cell niche in vivo where tumour cells can preserve the potential to proliferate and sustain the malignant process. (D) Paracrine effects of the secretome contributes to the duality function of MSCs. For example, they decrease levels in Stat 3 and IGF-1R, and increase levels of IL-4 and IL-10 to inhibit tumour growth, while also increasing levels of IL-6 and VEGF to promote tumour growth. https://biorender.com/ created the figure. MSCs, mesenchymal stem cells; CAF, cancer-associated fibroblasts; Stat3, signal transducer and activator of transcription 3; IGF-1R, insulin-like growth factor 1 receptor; IL-4, interleukin-4; IL-10, interleukin-10; IL-6, interleukin-6; VEGF, vascular endothelial growth factor; PDGF, platelet-derived growth factor; GM-CSF, granulocyte/macrophage colony stimulating factor.

tissue, and umbilical cord (134). The study found that the conditioned media of MSCs showed an increase in IL-4 and IL-10 but a decrease in granulocyte/macrophage colony-stimulating factor (GM-CSF), IL-6, and IL-9. It is undeniable that anti-inflammatory cytokines play an important role in cancers (135-137). However, controversial findings have been reported regarding whether cytokines support or hinder tumour progression (138-141). Regardless, MSCs have been shown to modulate the immune response through the balanced secretion of proinflammatory and anti-inflammatory cytokines (142). Therefore, this duality of function found in the secretome of MSCs and the complex cell-to-cell interaction between MSCs and cancer cells might be the reason for the conflicting reports regarding the role of MSCs in cancers.

Although the underlying mechanisms are not yet fully understood, there is a consensus that the differences in experimental design, e.g., tumour models used, route of cell administration, control group, tissue source, dosage use, and timing of the treatment that may affect the final results, should be considered $(37,117-119,143,144)$. Research should not make conclusions about the utility of MSCs in cancer therapy based on a single study. Instead, standardized protocols should be established to ensure that the data obtained are more comparable to understand the interaction of MSCs with cancer cells. Additionally, precautions should be taken before the clinical introduction of MSCs for treating cancers since the heterogeneous characteristics of MSCs are easily susceptible to different pathological conditions present in patients, which can hinder the therapeutic mechanisms.

\section{Potential strategy in utilizing MSCs for cancer therapy}

MSCs are recognized for their ability to migrate towards tumour sites $(145,146)$, but the literature to support the direct use of MSCs to treat cancer patients remains insufficient. MSCs can play a prominent role in reducing cancer progression since efficient intracellular tracking and directed delivery to the targeted site improve the pharmacological properties of anticancer drugs $(147,148)$. One of the earliest studies developing MSCs for the delivery of biological agents found that MSCs genetically modified to express interferon- $\beta$ (IFN- $\beta$ ) lowered tumour growth and doubled the survival rate of mice compared to the control group (149). In addition, IFN- $\beta$-transfected MSCs administered cisplatin triggered a high level of apoptosis in a melanoma xenograft mouse model (150). IFN- $\beta$-modified MSCs derived from the human umbilical cord were also reported to induce apoptosis in MDA-MB-231 cells (151). Tumour necrosis factor (TNF)-related apoptosis-inducing ligand (TRAIL) is a promising target that selectively induces 
apoptosis in cancer cells. TRAIL-modified MSCs have been reported to exert antitumour effects in different cancer cell lines and a mouse melanoma model (152-156). In addition, MSCs have been genetically modified to deliver other cytokines, e.g., IFN- $\gamma$ (156), IL-2 (157), IL-12 (158), and IL-24 (159), for antitumour effects.

Numerous studies have been conducted to explore the possibility of enhancing the inherent therapeutic properties of MSCs using genetic engineering. These studies mainly focused on four crucial points: improving migration, adhesion, and survivability while reducing the cell senescence of transplanted MSCs (160-162). This phenomenon is accomplished by inserting a vector loaded with a constructed genetic cassette into MSCs; the cassette expresses certain genes constantly or can be controlled with a gene switch (163). For example, adipose-derived MSCs (AdMSCs) were transduced with a retroviral vector to upregulate the expression of CXCR4. The study reported that the transduced MSCs showed increased motility, invasion, and placement in the bone marrow when injected into nonobese diabetic/severe combined immunodeficiency (NOD/SCID) mice (164). In addition to CXCR4, other genes involved in MSC migration, e.g., aquaporin-1, can be modified. It was reported that the overexpression of aquaporin-1 and CXCR4 promoted the migratory ability of MSCs via the Akt and Erk pathways (165). MSCs have also been genetically engineered to overexpress integrin-linked kinase (ILK). The study found that genetically modified MSCs had 1.5 -fold higher survivability and a $32.3 \%$ higher adhesion rate when engrafted into an ischaemic myocardium model, with a higher retention rate of $\sim 4$-fold (166). In addition, BMSCs and AdMSCs were reported to have increased proliferation and differentiation potential when engineered to overexpress Oct4 and Sox2 (167,168). Genetic engineering has the potential to circumvent the current problems that limit the application of MSCs in clinical settings and improve their potential therapeutic properties. Despite the immense benefits, this technique also has potential drawbacks, e.g., the risk of insertional oncogenesis due to viral vectors to introduce plasmid DNA, adverse immune reactions, and high production costs (169). Great precautions should be taken when considering the use of genetically modified MSCs for cancer therapy.

In addition, previous studies have established a connection between specific Toll-like receptors (TLRs) and the immunomodulatory properties of MSCs (170-172). Interestingly, a study reported that TLR-4-primed MSCs (MSC1) exhibited a proinflammatory phenotype, while TLR-3-primed MSCs (MSC2) secreted immunosuppressive mediators (173). Indeed, the polarization of MSCs into specific immunomodulatory phenotypes is a promising strategy as well. For example, macrophages cocultured with MSCs showed evidence of alternatively activated macrophages with high levels of CD206 and IL-10 but low levels of IL-12, which displayed a higher level of phagocytic activity (174). Studies have also reported that TL-3- and TL-4-primed MSCs preserved and enhanced the function of neutrophils through the combined action of IL-6, IFN- $\beta$, and GM-CSF $(175,176)$. Furthermore, MSC1 was observed to recruit lymphocytes by activating T-cells and secreting macrophage inflammatory protein-1 (MIP-1), CCL5, CXCL9, and CXCL9 (177). In contrast, MSCs can change macrophages from a TNF $\alpha$-secreting MSC1 phenotype to an immunosuppressive IL-10-expressing phenotype through a
prostaglandin-(PGE-)2-based mechanism (178). MSCs have also been reported to inhibit IL-2-induced NK cell proliferation and prevent the initiation of effector functions, e.g., cytotoxic activity and cytokine production, with the production of the soluble factors indoleamine 2,3-dioxygenase (IDO) and prostaglandin E2 (PGE2) (179). MSCs influence tumour growth through immunomodulation, and as discussed earlier, the polarization of MSCs for cancer treatment warrants further investigation. After all, it is widely accepted that chronic inflammation is a critical hallmark of cancer that elevates the risk of malignancy (180). The anti-inflammatory cytokines secreted by MSCs can circumvent these effects. On the other hand, tumour cells evade the immune system by avoiding immune recognition and developing an immunosuppressive microenvironment (181), which can be overcome with the help of MSCs boosting the innate immune system. Therefore, careful and purposeful polarization will benefit the field of cancer therapy and facilitate manipulation of the immunomodulatory capacity of MSCs.

Studies have also investigated the potential of MSCs to act as vectors for oncolytic viruses. For example, MSCs were used as vectors to deliver oncolytic herpes simplex virus to human brain melanoma metastasis models grown in immunodeficient and immunocompetent mice. This study reported that the intervention significantly prolonged the life of the mice through immunomodulatory actions compared to the control group (182). A recent in vivo study also explored the possibility of using MSCs derived from menstrual blood as a vector for CRAd5/F11 chimaeric oncolytic adenovirus to treat colorectal cancer. It was reported that the chimaeric oncolytic adenovirus was successfully delivered and accumulated at the tumour site, and it inhibited tumour growth (183). A mathematical model to quantitatively predict the efficacy of MSCs acting as vectors for virotherapeutic agents in vivo has been developed, indicating that MSCs are a promising strategy that improves the efficacy and safety profile of the treatment (184).

MSCs can also be primed with anticancer drugs for targeted delivery due to their preferential migration towards the tumour site and relative resistance to cytostatic and cytotoxic drugs (185-187). For example, MSCs acquire strong antitumour activity after packaging and delivering paclitaxel (PTX) through extracellular vesicles (188). The same study also demonstrated that it is possible to produce drugs with higher cell-target specificity by utilizing MSCs as a factory to package the drugs. Similar studies reported that MSCs isolated from different sources were primed with PTX and tested against different cancer cell lines (187,189-191). Other drugs were also tested for priming MSCs, e.g., doxorubicin and gemcitabine. A study reported similar results whereby MSCs effectively incorporated the active form of the drugs and released sufficient quantities to produce a significant inhibition of squamous cell carcinoma growth in vitro (192). Researchers have explored the possibility of using nanoparticles to improve the payload and delivery capacity of MSCs $(193,194)$. All of these studies indicate that MSCs are able to take up and subsequently release drugs in a targeted and gradual manner, which improves the efficacy of anticancer drugs.

Due to the short half-life of most anticancer drugs in the body and their high toxicity to healthy cells, direct 


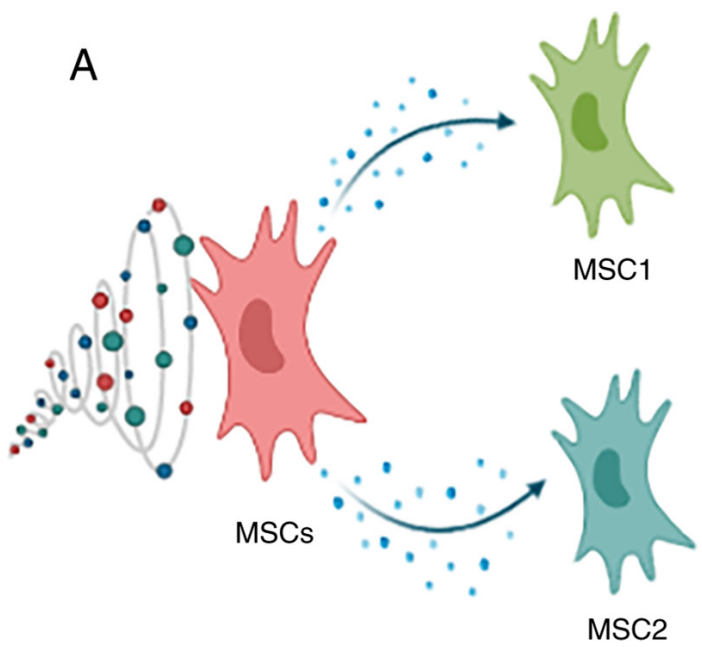

Priming for immunomodulatory phenotype

C

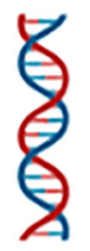

DNA

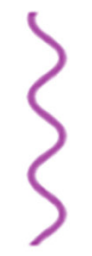

mRNA

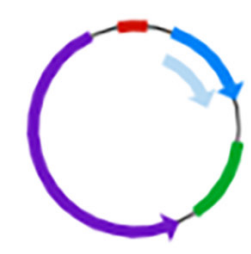

Viral plasmid
B

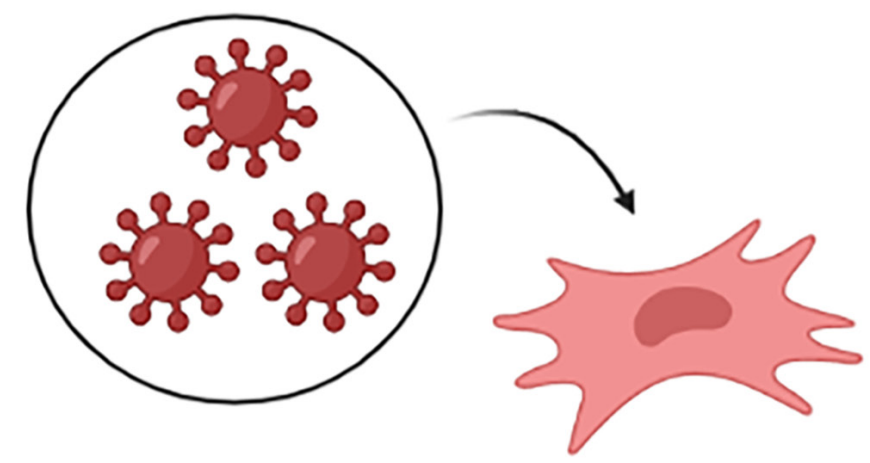

Vector for oncolytic virus

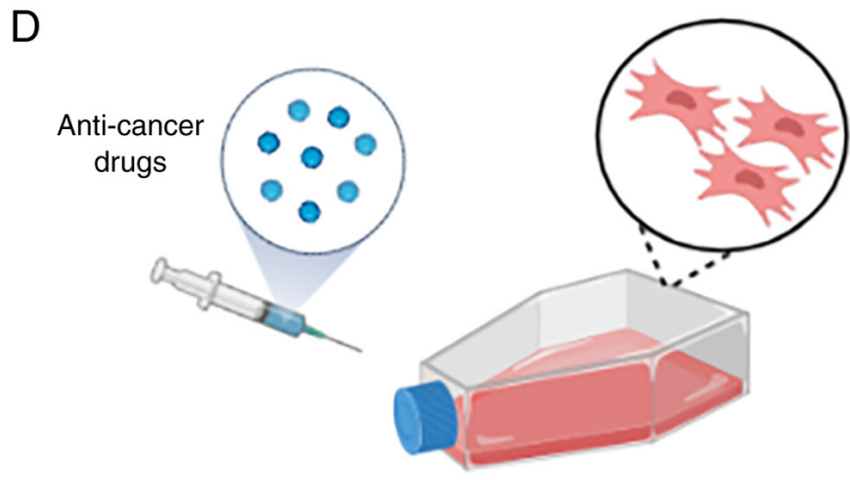

Genetic engineering

Figure 2. Potential therapeutic strategies of MSCs in cancer therapy. (A) Priming TLR-4-primed MSCs (MSC1) and TLR-3-primed MSCs (MSC2) for the immunomodulatory phenotype. (B) Vector delivers the oncolytic virus to the tumour site for growth inhibition. (C) Genetic engineering using viral vectors to introduce plasmid RNA and DNA. (D) Priming MSCs with anticancer drugs to improve their pharmacological properties. https://biorender.com/ created the figure. MSCs, mesenchymal stem cells; TLR, Toll-like receptor.

administration of these drugs is often associated with unwanted side effects. For example, nausea and vomiting, tiredness, changes in taste, dry mouth, loss of appetite, constipation, and hair loss are common side effects faced by chemotherapy patients (195). Thus, using MSCs as vectors to deliver therapeutic proteins or anticancer drugs can help to solve this issue advantageously. MSCs can exert therapeutic effects locally due to selective migration and accumulation in tumour sites, increasing treatment efficacy and reducing systemic toxicity. Currently, divergent drugs are being investigated for different cancer therapeutic purposes. For example, MSCs were reported to enhance the therapeutic capabilities of tendon repair when pretreated with pioglitazone (196). Other studies using pioglitazone as the priming agent also found similar results, where pretreated MSCs had greater therapeutic effects on lung regeneration in an emphysema mouse model $(197,198)$. Pioglitazone has been administered indirectly to breast cancer cells via stem-and-cancer cell interaction (199). Through this process, modified and viable pretreated stem cells are subsequently administered to patients, and pretreated stem cells are allowed to interact with cancer cells in the patients' bodies. Considering that pioglitazone has been reported to possess anticancer effects (200-202), it may be beneficial to examine the possibility of priming MSCs with pioglitazone for cancer therapy. After all, using MSCs pretreated with pioglitazone as a strategy to improve the overall therapeutic effects, as reported in our study (199), remains rare. Despite the study on cardiomyogenic transdifferentiation and cardiac function (203), as mentioned above, MSCs pretreated with pioglitazone for cancer therapy remain to be characterized. A similar strategy was conducted using AdMSCs pretreated with a peroxisome proliferator-activated receptor gamma (PPAR $\gamma$ ) agonist to improve the regeneration effects in an elastase-induced emphysema mouse model (197). Indeed, human umbilical cord-derived mesenchymal stem cells pretreated with IL- 6 were also found to abolish the stem cell growth-promoting effect on gastric cancer cells (204). The potential therapeutic strategies of MSCs in cancer therapy are summarized in Fig. 2.

Although the potential benefit is undeniable, there are potential risks in using MSCs for cancer treatments. These risks can be categorized as acute issues, e.g., inflammatory reaction or embolic phenomenon, intermediate issues, e.g., graft-versus-host disease (GVHD) or secondary infection, or long-term issues, e.g., risk of tumour growth (142). It was reported in a clinical study that patients treated 
with MSCs commonly died due to infection (205). This phenomenon, coupled with the fact that MSCs can potentially promote tumour growth instead of inhibiting it, as previously discussed, makes it a risky treatment option. However, more studies must be conducted to provide future evidence and improve the therapeutic effects of modified MSCs in cancer treatments. These cells hold great potential to revolutionize the current cancer therapies that are available.

\section{Concluding remarks and future perspectives}

It is undeniable that stem cells are promising therapeutic alternatives for numerous human diseases. While the motivation to benefit human health is noble, researchers should take precautions in this field to prevent the potential exploitation of vulnerable groups. Efforts should also be directed towards using MSCs in autologous and allogeneic transplantation, as they do not raise the same ethical concerns as ESCs. In addition, MSCs benefit from their ability to carry anticancer payloads through genetic manipulation or pretreatment of the cells, leading to use in regenerative medicine and potentially oncology. Therefore, it is important to obtain as much information as possible to ensure that stem cell-based therapy is reliable, effective, efficient, safe, and affordable. It should be developed with the physiological condition of the patients in mind to truly benefit humanity.

\section{Acknowledgements}

Not applicable.

\section{Funding}

The present project was funded by the Exploratory Research Grant Scheme Fasa 1/2013 (grant no. 203/CIPPM/6730098).

\section{Availability of data and materials}

Not applicable.

\section{Authors' contributions}

SKL and BYK contributed to the conception and design of the study. SKL drafted the manuscript and BYK revised the manuscript. Both authors have read and approved the final manuscript. Data sharing is not applicable.

\section{Ethics approval and consent to participate}

Not applicable.

\section{Patient consent for publication}

Not applicable.

\section{Competing interests}

The authors declare that they have no competing interests.

\section{References}

1. Watt FM and Driskell RR: The therapeutic potential of stem cells. Philos Trans R Soc B Biol Sci 365: 155-163, 2010.

2. Alvarez CV, Garcia-Lavandeira M, Garcia-Rendueles MER, Diaz-Rodriguez E, Garcia-Rendueles AR, Perez-Romero S, Vila TV, Rodrigues JS, Lear PV and Bravo SB: Defining stem cell types: Understanding the therapeutic potential of ESCs, ASCs, and iPS cells. J Mol Endocrinol 49: R89-R111, 2012.

3. Zakrzewski W, Dobrzyński M, Szymonowicz M and Rybak Z Stem cells: Past, present, and future. Stem Cell Res Ther 10: 68, 2019.

4. Singh VK, Saini A, Kalsan M, Kumar N and Chandra R Describing the stem cell potency: The various methods of functional assessment and in silico diagnostics. Front Cell Dev Biol 4: 134,2016

5. Pittenger MF, Discher DE, Péault BM, Phinney DG, Hare JM and Caplan AI: Mesenchymal stem cell perspective: Cell biology to clinical progress. NPJ Regen Med 4: 22, 2019.

6. Martin GR: Isolation of a pluripotent cell line from early mouse embryos cultured in medium conditioned by teratocarcinoma stem cells. Proc Natl Acad Sci USA 78: 7634-7638, 1981.

7. Friedenstein AJ, Chailakhjan RK and Lalykina KS: The development of fibroblast colonies in monolayer cultures of guinea-pig bone marrow and spleen cells. Cell Tissue Kinet 3: 393-403, 1970.

8. Thomson JA, Itskovitz-Eldor J, Shapiro SS, Waknitz MA Swiergiel JJ, Marshall VS and Jones JM: Embryonic stem cell lines derived from human blastocysts. Science 282: 1145-1147, 1998.

9. Haynesworth SE, Goshima J, Goldberg VM and Caplan AI: Characterization of cells with osteogenic potential from human marrow. Bone 13: 81-88, 1992

10. McLeod C and Baylis F: Feminists on the inalienability of human embryos. Hypatia 21: 1-14, 2006.

11. Caulfield T and Ogbogu U: Stem cell research, scientific freedom and the commodification concern. EMBO Rep 13: 12-16, 2012.

12. Marway H,Johnson SL and Widdows H: Commodification of human tissue. In: Handbook of Global Bioethics. ten Have H.A.M.J. and Gordijn B (eds). Springer Netherlands, Dordrecht, Netherlands, pp 581-598, 2014.

13. Lee JS, Hong JM, Moon GJ, Lee PH, Ahn YH and Bang OY; STARTING collaborators: A long-term follow-up study of intravenous autologous mesenchymal stem cell transplantation in patients with ischemic stroke. Stem Cells 28: 1099-1106, 2010.

14. Bhasin A, Srivastava MVP, Kumaran SS, Mohanty S, Bhatia R, Bose S, Gaikwad S, Garg A and Airan B: Autologous mesenchymal stem cells in chronic stroke. Cerebrovasc Dis Extra 1: 93-104, 2011.

15. Honmou O, Houkin K, Matsunaga T, Niitsu Y, Ishiai S, Onodera R, Waxman SG and Kocsis JD: Intravenous administration of auto serum-expanded autologous mesenchymal stem cells in stroke. Brain 134 (Pt 6): 1790-1807, 2011.

16. Connick P, Kolappan M, Crawley C, Webber DJ, Patani R, Michell AW, Du MQ, Luan SL, Altmann DR, Thompson AJ, et al: Autologous mesenchymal stem cells for the treatment of secondary progressive multiple sclerosis: An open-label phase $2 \mathrm{a}$ proof-of-concept study. Lancet Neurol 11: 150-156, 2012.

17. Weiss DJ, Casaburi R, Flannery R, LeRoux-Williams M and Tashkin DP: A placebo-controlled, randomized trial of mesenchymal stem cells in COPD. Chest 143: 1590-1598, 2013.

18. Götherström C, Westgren M, Shaw SWS, Aström E, Biswas A, Byers PH, Mattar CNZ, Graham GE, Taslimi J, Ewald U, et al: Pre- and postnatal transplantation of fetal mesenchymal stem cells in osteogenesis imperfecta: A two-center experience. Stem Cells Transl Med 3: 255-264, 2014.

19. Heldman AW, DiFede DL, Fishman JE, Zambrano JP, Trachtenberg BH, Karantalis V, Mushtaq M, Williams AR, Suncion VY, McNiece IK, et al: Transendocardial mesenchymal stem cells and mononuclear bone marrow cells for ischemic cardiomyopathy: The TAC-HFT randomized trial. JAMA 311: $62-73,2014$

20. Karantalis V, DiFede DL, Gerstenblith G, Pham S, Symes J, Zambrano JP, Fishman J, Pattany P, McNiece I, Conte J, et al: Autologous mesenchymal stem cells produce concordant improvements in regional function, tissue perfusion, and fibrotic burden when administered to patients undergoing coronary artery bypass grafting: The prospective randomized study of mesenchymal stem cell therapy in patients undergoing cardiac surgery (PROMETHEUS) trial. Circ Res 114: 1302-1310, 2014. 
21. Rushkevich YN, Kosmacheva SM, Zabrodets GV, Ignatenko SI, Goncharova NV, Severin IN, Likhachev SA and Potapnev MP. The use of autologous mesenchymal stem cells for cell therapy of patients with amyotrophic lateral sclerosis in Belarus. Bull Exp Biol Med 159: 576-581, 2015.

22. Thakkar UG, Trivedi HL, Vanikar AV and Dave SD Insulin-secreting adipose-derived mesenchymal stromal cells with bone marrow-derived hematopoietic stem cells from autologous and allogenic sources for type 1 diabetes mellitus. Cytotherapy 17: 940-947, 2015.

23. Vega A, Martín-Ferrero MA, Del Canto F, Alberca M, García V, Munar A, Orozco L, Soler R, Fuertes JJ, Huguet M, et al: Treatment of knee osteoarthritis with allogeneic bone marrow mesenchymal stem cells: A randomized controlled trial. Transplantation 99: 1681-1690, 2015.

24. Fernández O, Izquierdo G, Fernández V, Leyva L, Reyes V, Guerrero M, León A, Arnaiz C, Navarro G, Páramo MD, et al: Adipose-derived mesenchymal stem cells (AdMSC) for the treatment of secondary-progressive multiple sclerosis: A triple blinded, placebo controlled, randomized phase I/II safety and feasibility study. PLoS One 13: e0195891, 2018.

25. Musiał-Wysocka A, Kot M and Majka M: The pros and cons of mesenchymal stem cell-based therapies. Cell Transplant 28 : 801-812, 2019.

26. Hmadcha A, Martin-Montalvo A, Gauthier BR, Soria B and Capilla-Gonzalez V: Therapeutic potential of mesenchymal stem cells for cancer therapy. Front Bioeng Biotechnol 8: 43 2020.

27. da Silva Meirelles L, Chagastelles PC and Nardi NB Mesenchymal stem cells reside in virtually all post-natal organs and tissues. J Cell Sci 119 (Pt 11): 2204-2213, 2006.

28. Secunda R, Vennila R, Mohanashankar AM, Rajasundari M, Jeswanth S and Surendran R: Isolation, expansion and characterisation of mesenchymal stem cells from human bone marrow, adipose tissue, umbilical cord blood and matrix: A comparative study. Cytotechnology 67: 793-807, 2015.

29. Dominici M, Le Blanc K, Mueller I, Slaper-Cortenbach I, Marini F, Krause D, Deans R, Keating A, Prockop D and Horwitz E: Minimal criteria for defining multipotent mesenchymal stromal cells. The international society for cellular therapy position statement. Cytotherapy 8: 315-317, 2006.

30. Viswanathan S, Shi Y, Galipeau J, Krampera M, Leblanc K, Martin I, Nolta J, Phinney DG and Sensebe L: Mesenchymal stem versus stromal cells: International society for cell \& gene therapy (ISCT ${ }^{\circledR}$ ) mesenchymal stromal cell committee position statement on nomenclature. Cytotherapy 21: 1019-1024, 2019.

31. Păunescu V, Deak E, Herman D, Siska IR, Tănasie G, Bunu C, Anghel S, Tatu CA, Oprea TI, Henschler R, et al: In vitro differentiation of human mesenchymal stem cells to epithelial lineage. J Cell Mol Med 11: 502-508, 2007.

32. Quevedo HC, Hatzistergos KE, Oskouei BN, Feigenbaum GS, Rodriguez JE, Valdes D, Pattany PM, Zambrano JP, Hu Q, McNiece I, et al: Allogeneic mesenchymal stem cells restore cardiac function in chronic ischemic cardiomyopathy via trilineage differentiating capacity. Proc Natl Acad Sci USA 106: 14022-14027, 2009.

33. Gervois P, Struys T, Hilkens P, Bronckaers A, Ratajczak J, Politis C, Brône B, Lambrichts I and Martens W: Neurogenic maturation of human dental pulp stem cells following neurosphere generation induces morphological and electrophysiological characteristics of functional neurons. Stem Cells Dev 24: 296-311, 2015.

34. Mishra PJ, Mishra PJ, Humeniuk R, Medina DJ, Alexe G, Mesirov JP, Ganesan S, Glod JW and Banerjee D Carcinoma-associated fibroblast-like differentiation of human mesenchymal stem cells. Cancer Res 68: 4331-4339, 2008.

35. Jotzu C, Alt E, Welte G, Li J, Hennessy BT, Devarajan E, Krishnappa S, Pinilla S, Droll L and Song YH: Adipose tissue-derived stem cells differentiate into carcinoma-associated fibroblast-like cells under the influence of tumor-derived factors. Anal Cell Pathol (Amst) 33: 61-79, 2010.

36. Miyazaki Y, Oda T, Inagaki Y, Kushige H, Saito Y, Mori N, Takayama Y, Kumagai Y, Mitsuyama T and Kida YS: Adipose-derived mesenchymal stem cells differentiate into heterogeneous cancer-associated fibroblasts in a stroma-rich xenograft model. Sci Rep 11: 4690, 2021.

37. Lee MW, Ryu S, Kim DS, Lee JW, Sung KW, Koo HH and Yoo KH: Mesenchymal stem cells in suppression or progression of hematologic malignancy: Current status and challenges. Leukemia 33: 597-611, 2019.
38. Liang W, Chen X, Zhang S, Fang J, Chen M, Xu Y and Chen X: Mesenchymal stem cells as a double-edged sword in tumor growth: Focusing on MSC-derived cytokines. Cell Mol Biol Lett 26: 3, 2021.

39. Bellagamba BC, de Abreu BRR, Grivicich I, Markarian CF, Chem E, Camassola M, Nardi NB and Dihl RR: Human mesenchymal stem cells are resistant to cytotoxic and genotoxic effects of cisplatin in vitro. Genet Mol Biol 39: 129-134, 2016.

40. Honczarenko M, Le Y, Swierkowski M, Ghiran I, Glodek AM and Silberstein LE: Human bone marrow stromal cells express a distinct set of biologically functional chemokine receptors. Stem Cells 24: 1030-1041, 2006.

41. Lee RH, Seo MJ, Pulin AA, Gregory CA, Ylostalo J and Prockop DJ: The CD34-like protein PODXL and alpha6-integrin (CD49f) identify early progenitor MSCs with increased clonogenicity and migration to infarcted heart in mice. Blood 113 : 816-826, 2009.

42. Williams SA, Maecker HL, French DM, Liu J, Gregg A, Silverstein LB, Cao TC, Carano RAD and Dixit VM: USP1 deubiquitinates ID proteins to preserve a mesenchymal stem cell program in osteosarcoma. Cell 146: 918-930, 2011.

43. Zhuo L, Gong J, Yang R, Sheng Y, Zhou L, Kong X and Cao K: Inhibition of proliferation and differentiation and promotion of apoptosis by cyclin L2 in mouse embryonic carcinoma P19 cells. Biochem Biophys Res Commun 390: 451-457, 2009.

44. Puchert $\mathrm{M}$ and Engele J: The peculiarities of the SDF-1/CXCL12 system: In some cells, CXCR4 and CXCR7 sing solos, in others, they sing duets. Cell Tissue Res 355: 239-253, 2014.

45. Janssens R, Struyf S and Proost P: The unique structural and functional features of CXCL12. Cell Mol Immunol 15: 299-311, 2018.

46. De La Luz Sierra M, Yang F, Narazaki M, Salvucci O, Davis D, Yarchoan R, Zhang HH, Fales H and Tosato G: Differential processing of stromal-derived factor-1alpha and stromal-derived factor-1beta explains functional diversity. Blood 103: 2452-2459, 2004.

47. Gomes AC, Hara T, Lim VY, Herndler-Brandstetter D, Nevius E, Sugiyama T, Tani-ichi S, Schlenner S, Richie E, Rodewald HR, et al: Hematopoietic stem cell niches produce lineage-instructive signals to control multipotent progenitor differentiation. Immunity 45: 1219-1231, 2016.

48. Reid JC, Tanasijevic B, Golubeva D, Boyd AL, Porras DP, Collins TJ and Bhatia M: CXCL12/CXCR4 signaling enhances human PSC-derived hematopoietic progenitor function and overcomes early in vivo transplantation failure. Stem Cell Reports 10 $1625-1641,2018$

49. Binder ZA, Siu IM, Eberhart CG, Rhys CA, Bai RY, Staedtke V, Zhang H, Smoll NR, Piantadosi S, Piccirillo SG, et al: Podocalyxin-like protein is expressed in glioblastoma multiforme stem-like cells and is associated with poor outcome. PLoS One 8: e75945, 2013.

50. Chang J, Liu F, Lee M, Wu B, Ting K, Zara JN, Soo C, Hezaimi KA, Zou W, Chen X, et al: NF- $\kappa$ B inhibits osteogenic differentiation of mesenchymal stem cells by promoting $\beta$-catenin degradation. Proc Natl Acad Sci 110: 9469-9474, 2013.

51. Kolosova IA, Angelini D, Fan C, Skinner J, Cheadle C and Johns RA: Resistin-like molecule $\alpha$ stimulates proliferation of mesenchymal stem cells while maintaining their multipotency. Stem Cells Dev 22: 239-247, 2013.

52. Chosa $\mathrm{N}$ and Ishisaki A: Two novel mechanisms for maintenance of stemness in mesenchymal stem cells: SCRG1/BST1 axis and cell-cell adhesion through N-cadherin. Jpn Dent Sci Rev 54: 37-44, 2018.

53. Sugiyama T, Kohara H, Noda M and Nagasawa T: Maintenance of the hematopoietic stem cell pool by CXCL12-CXCR4 chemokine signaling in bone marrow stromal cell niches. Immunity 25: 977-988, 2006.

54. Gharibi B, Ghuman MS and Hughes FJ: Akt- and Erk-mediated regulation of proliferation and differentiation during PDGFR $\beta$-induced MSC self-renewal. J Cell Mol Med 16: 2789-2801,2012.

55. Takebe N, Miele L, Harris PJ, Jeong W, Bando H, Kahn M, Yang SX and Ivy SP: Targeting Notch, hedgehog, and wnt pathways in cancer stem cells: Clinical update. Nat Rev Clin Oncol 12: 445-464, 2015

56. Batsali AK, Pontikoglou C, Koutroulakis D, Pavlaki KI, Damianaki A, Mavroudi I, Alpantaki K, Kouvidi E, Kontakis G and Papadaki HA: Differential expression of cell cycle and WNT pathway-related genes accounts for differences in the growth and differentiation potential of Wharton's jelly and bone marrow-derived mesenchymal stem cells. Stem Cell Res Ther 8: 102, 2017. 
57. Pelullo M, Zema S, Nardozza F, Checquolo S, Screpanti I and Bellavia D: Wnt, Notch, and TGF- $\beta$ pathways impinge on Hedgehog signaling complexity: An open window on cancer. Front Genet 10: 711, 2019.

58. Wagner W, Horn P, Castoldi M, Diehlmann A, Bork S, Saffrich R, Benes V, Blake J, Pfister S, Eckstein V and Ho AD: Replicative senescence of mesenchymal stem cells: A continuous and organized process. PLoS One 3: e2213, 2008.

59. Halfon S, Abramov N, Grinblat B and Ginis I: Markers distinguishing mesenchymal stem cells from fibroblasts are downregulated with passaging. Stem Cells Dev 20: 53-66, 2011.

60. Pérez-Campo FM and Riancho JA: Epigenetic mechanisms regulating mesenchymal stem cell differentiation. Curr Genomics 16 368-383, 2015

61. Teven CM, Liu X, Hu N, Tang N, Kim SH, Huang E, Yang K, Li M, Gao JL, Liu H, et al: Epigenetic regulation of mesenchymal stem cells: A focus on osteogenic and adipogenic differentiation. Stem Cells Int 2011: 201371,2011.

62. Srinageshwar B, Maiti P, Dunbar GL and Rossignol J: Role of epigenetics in stem cell proliferation and differentiation: Implications for treating neurodegenerative diseases. Int J Mol Sci 17: 199, 2016.

63. Escacena N, Quesada-Hernández E, Capilla-Gonzalez V, Soria B and Hmadcha A: Bottlenecks in the efficient use of advanced therapy medicinal products based on mesenchymal stromal cells. Stem Cells Int 2015: 895714, 2015

64. Zhang D and Kilian KA: The effect of mesenchymal stem cell shape on the maintenance of multipotency. Biomaterials 34: 3962-3969, 2013

65. Rathbone SR, Glossop JR, Gough JE and Cartmell SH: Cyclic tensile strain upon human mesenchymal stem cells in 2D and 3D culture differentially influences CCNL2, WDR61 and BAHCC1 gene expression levels. J Mech Behav Biomed Mater 11: 82-91, 2012 .

66. Cao C, Li L, Li H, He X, Wu G and Yu X: Cyclic biaxial tensile strain promotes bone marrow-derived mesenchymal stem cells to differentiate into cardiomyocyte-like cells by miRNA-27a. Int J Biochem Cell Biol 99: 125-132, 2018.

67. Zhang L, Wang Y, Zhou N, Feng Y and Yang X: Cyclic tensile stress promotes osteogenic differentiation of adipose stem cells via ERK and p38 pathways. Stem Cell Res 37: 101433, 2019.

68. Lazarus HM, Haynesworth SE, Gerson SL, Rosenthal NS and Caplan AI: Ex vivo expansion and subsequent infusion of human bone marrow-derived stromal progenitor cells (mesenchymal progenitor cells): Implications for therapeutic use. Bone Marrow Transplant 16: 557-564, 1995

69. Galipeau J and Sensébé L: Mesenchymal stromal cells: Clinical challenges and therapeutic opportunities. Cell Stem Cell 22: 824-833, 2018

70. Lukomska B, Stanaszek L, Zuba-Surma E, Legosz P, Sarzynska S and Drela K: Challenges and controversies in human mesenchymal stem cell therapy. Stem Cells Int 2019: 9628536, 2019.

71. Gálvez P, Clares B, Bermejo M, Hmadcha A and Soria B: Standard requirement of a microbiological quality control program for the manufacture of human mesenchymal stem cells for clinical use. Stem Cells Dev 23: 1074-1083, 2014.

72. Galvez-Martin P, Sabata R, Verges J, Zugaza JL, Ruiz A and Clares B: Mesenchymal stem cells as therapeutics agents: Quality and environmental regulatory aspects. Stem Cells Int 2016: 9783408, 2016

73. Yang YHK: Aging of mesenchymal stem cells: Implication in regenerative medicine. Regen Ther 9: 120-122, 2018.

74. Fafián-Labora JA, Morente-López M and Arufe MC: Effect of aging on behaviour of mesenchymal stem cells. World J Stem Cells 11: 337-346, 2019

75. Huang XP, Sun Z, Miyagi Y, McDonald KH, Zhang L, Weisel RD and Li RK: Differentiation of allogeneic mesenchymal stem cells induces immunogenicity and limits their long-term benefits for myocardial repair. Circulation 122: 2419-2429, 2010.

76. Cho PS, Messina DJ, Hirsh EL, Chi N, Goldman SN, Lo DP Harris IR, Popma SH, Sachs DH and Huang CA: Immunogenicity of umbilical cord tissue-derived cells. Blood 111: 430-438, 2008

77. Faiella W and Atoui R: Immunotolerant properties of mesenchymal stem cells: Updated review. Stem Cells Int 2016: 1859567, 2016.

78. Dhingra S, Li P, Huang XP, Guo J, Wu J, Mihic A, Li SH, Zang WF, Shen D, Weisel RD, et al: Preserving prostaglandin E2 level prevents rejection of implanted allogeneic mesenchymal stem cells and restores postinfarction ventricular function. Circulation 128 (11 Suppl 1): S69-S78, 2013.
79. Gu Z, Tan W, Ji J, Feng G, Meng Y, Da Z, Guo G, Xia Y, Zhu X, Shi $G$ and Cheng C: Rapamycin reverses the senescent phenotype and improves immunoregulation of mesenchymal stem cells from MRL/lpr mice and systemic lupus erythematosus patients through inhibition of the mTOR signaling pathway. Aging (Albany NY) 8: 1102-1114, 2016.

80. Ankrum JA, Ong JF and Karp JM: Mesenchymal stem cells: Immune evasive, not immune privileged. Nat Biotechnol 32: 252-260, 2014

81. Zazzeroni L, Lanzoni G, Pasquinelli G and Ricordi C Considerations on the harvesting site and donor derivation for mesenchymal stem cells-based strategies for diabetes. CellR4 Repair Replace Regen Reprogram. 5: e2435, 2017.

82. Gao L, Bird AK, Meednu N, Dauenhauer K, Liesveld J, Anolik J and Looney RJ: Bone marrow-derived mesenchymal stem cells from patients with systemic lupus erythematosus have a senescence-associated secretory phenotype mediated by a mitochondrial antiviral signaling protein-interferon- $\beta$ feedback loop. Arthritis Rheumatol 69: 1623-1635, 2017.

83. Ji J, Wu Y, Meng Y, Zhang L, Feng G, Xia Y, Xue W, Zhao S, $\mathrm{Gu} Z$ and Shao X: JAK-STAT signaling mediates the senescence of bone marrow-mesenchymal stem cells from systemic lupus erythematosus patients. Acta Biochim Biophys Sin (Shanghai) 49: 208-215, 2017

84. Zhu Y and Feng X: Genetic contribution to mesenchymal stem cell dysfunction in systemic lupus erythematosus. Stem Cell Res Ther 9: 149, 2018.

85. Chen DC, Lin SZ, Fan JR, Lin CH, Lee W, Lin CC, Liu YJ, Tsai CH, Chen JC, Cho DY, et al: Intracerebral implantation of autologous peripheral blood stem cells in stroke patients: A randomized phase II study. Cell Transplant 23: 1599-1612, 2014

86. Taguchi A, Sakai C, Soma T, Kasahara Y, Stern DM, Kajimoto K, Ihara M, Daimon T, Yamahara K, Doi K, et al: Intravenous autologous bone marrow mononuclear cell transplantation for stroke: Phase1/2a clinical trial in a homogeneous group of stroke patients. Stem Cells Dev 24: 2207-2218, 2015.

87. Hess DC, Wechsler LR, Clark WM, Savitz SI, Ford GA, Chiu D, Yavagal DR, Uchino K, Liebeskind DS, Auchus AP, et al: Safety and efficacy of multipotent adult progenitor cells in acute ischaemic stroke (MASTERS): A randomised, double-blind, placebo-controlled, phase 2 trial. Lancet Neurol 16: 360-368, 2017.

88. Bhatia V, Gupta V, Khurana D, Sharma RR and Khandelwal N: Randomized assessment of the safety and efficacy of intra-arterial infusion of autologous wtem cells in wubacute ischemic stroke. AJNR Am J Neuroradiol 39: 899-904, 2018.

89. Gautam J, Alaref A, Hassan A, Kandel RS, Mishra R and Jahan N: Safety and efficacy of stem cell therapy in patients with ischemic stroke. Cureus 12: e9917, 2020.

90. Trachtenberg B, Velazquez DL, Williams AR, McNiece I, Fishman J, Nguyen K, Rouy D, Altman P, Schwarz R, Mendizabal A, et al: Rationale and design of the transendocardial injection of autologous human cells (bone marrow or mesenchymal) in chronic ischemic left ventricular dysfunction and heart failure secondary to myocardial infarction (TAC-HFT) trial: A randomized, double-blind, placebo-controlled study of safety and efficacy. Am Heart J 161: 487-493, 2011

91. Mushtaq M, DiFede DL, Golpanian S, Khan A, Gomes SA, Mendizabal A, Heldman AW and Hare JM: Rationale and design of the percutaneous stem cell injection delivery effects on neomyogenesis in dilated cardiomyopathy (The POSEIDON-DCM Study). J Cardiovasc Transl Res 7: 769-780, 2014.

92. Hare JM, DiFede DL, Rieger AC, Florea V, Landin AM, El-Khorazaty J, Khan A, Mushtaq M, Lowery MH, Byrnes JJ, et al: Randomized comparison of allogeneic versus autologous mesenchymal stem cells for nonischemic dilated cardiomyopathy: POSEIDON-DCM Trial. J Am Coll Cardiol 69: 526-537, 2017.

93. Kidd S, Spaeth E, Dembinski JL, Dietrich M, Watson K, Klopp A, Battula L, Weil M, Andreeff M and Marini FC: Direct evidence of mesenchymal stem cell tropism for tumor and wounding microenvironments using in vivo bioluminescence imaging. Stem Cells 27: 2614-2623, 2009.

94. Sun X, Cheng G, Hao M, Zheng J, Zhou X, Zhang J, Taichman RS, Pienta KJ and Wang J: CXCL12/CXCR4/CXCR7 chemokine axis and cancer progression. Cancer Metastasis Rev 29: 709-722, 2010.

95. Spaeth E, Klopp A, Dembinski J, Andreeff M and Marini F: Inflammation and tumor microenvironments: Defining the migratory itinerary of mesenchymal stem cells. Gene Ther 15 : 730-738, 2008 
96. Kolaczkowska E and Kubes P: Neutrophil recruitment and function in health and inflammation. Nat Rev Immunol 13: 159-175, 2013.

97. Dimarino AM, Caplan AI and Bonfield TL: Mesenchymal stem cells in tissue repair. Front Immunol 4: 201, 2013

98. Ayala-Cuellar AP, Kang JH, Jeung EB and Choi KC: Roles of mesenchymal stem cells in tissue regeneration and immunomodulation. Biomol Ther (Seoul) 27: 25-33, 2019.

99. Julier Z, Park AJ, Briquez PS and Martino MM: Promoting tissue regeneration by modulating the immune system. Acta Biomater 53: 13-28, 2017.

100. Prockop DJ and Oh JY: Mesenchymal stem/stromal cells (MSCs): Role as guardians of inflammation. Mol Ther 20 : 14-20, 2012

101. Song J, Kang HJ, Ju HM, Park A, Park H, Hong JS, Kim CJ, Shim JY, Yu J and Choi J: Umbilical cord-derived mesenchymal stem cell extracts ameliorate atopic dermatitis in mice by reducing the $\mathrm{T}$ cell responses. Sci Rep 9: 6623, 2019.

102. Ren G, Zhao X, Zhang L, Zhang J, L'Huillier A, Ling W Roberts AI, Le AD, Shi S, Shao C and Shi Y: Inflammatory cytokine-induced intercellular adhesion molecule-1 and vascular cell adhesion molecule-1 in mesenchymal stem cells are critical for immunosuppression. J Immunol 184: 2321-2328, 2010.

103. Li Y, Zhang D, Xu L, Dong L, Zheng J, Lin Y, Huang J, Zhang Y, Tao Y, Zang X, et al: Cell-cell contact with proinflammatory macrophages enhances the immunotherapeutic effect of mesenchymal stem cells in two abortion models. Cell Mol Immunol 16 908-920, 2019.

104. Nitzsche F, Müller C, Lukomska B, Jolkkonen J, Deten A and Boltze J: Concise review: MSC adhesion cascade-insights into homing and transendothelial migration. Stem Cells 35: 1446-1460, 2017.

105. Caplan H, Olson SD, Kumar A, George M, Prabhakara KS, Wenzel P, Bedi S, Toledano-Furman NE, Triolo F, Kamhieh-Milz J, et al: Mesenchymal stromal cell therapeutic delivery: Translational challenges to clinical application. Front Immunol 10: 1645, 2019.

106. Ullah M, Liu DD and Thakor AS: Mesenchymal stromal cell homing: Mechanisms and strategies for improvement iScience 15: 421-438. 2019.

107. Fiore EJ,Domínguez LM, Bayo J, García MG and Mazzolini GD: Taking advantage of the potential of mesenchymal stromal cells in liver regeneration: Cells and extracellular vesicles as therapeutic strategies. World J Gastroenterol 24: 2427-2440, 2018.

108. Li H, Rong P, Ma X, Nie W, Chen C, Yang C, Zhang J, Dong Q and Wang W: Paracrine effect of mesenchymal stem cell as a novel therapeutic strategy for diabetic nephropathy. Life Sci 215 $113-118,2018$

109. Zheng G, Huang R, Qiu G, Ge M, Wang J, Shu Q and Xu J: Mesenchymal stromal cell-derived extracellular vesicles. Regenerative and immunomodulatory effects and potential applications in sepsis. Cell Tissue Res 374: 1-15, 2018.

110. Weiss ARR and Dahlke MH: Immunomodulation by mesenchymal stem cells (MSCs): Mechanisms of action of living, apoptotic, and dead MSCs. Front Immunol 10: 1191, 2019.

111. Coussens LM and Werb Z: Inflammation and cancer. Nature 420 860-867, 2002.

112. Wobus M, List C, Dittrich T, Dhawan A, Duryagina R Arabanian LS, Kast K, Wimberger P, Stiehler M, Hofbauer LC, et al: Breast carcinoma cells modulate the chemoattractive activity of human bone marrow-derived mesenchymal stromal cells by interfering with CXCL12. Int J Cancer 136: 44-54, 2015.

113. Kalimuthu S, Oh JM, Gangadaran P, Zhu L, Lee HW, Rajendran RL, Baek SH, Jeon YH, Jeong SY, Lee SW, et al In vivo tracking of chemokine receptor CXCR4-engineered mesenchymal stem cell migration by optical molecular imaging. Stem Cells Int 2017: 8085637, 2017

114. Ratajczak MZ, Bujko K, Mack A, Kucia M and Ratajczak J: Cancer from the perspective of stem cells and misappropriated tissue regeneration mechanisms. Leukemia 32: 2519-2526, 2018.

115. Suzuki K, Sun R, Origuchi M, Kanehira M, Takahata T, Itoh J, Umezawa A, Kijima H, Fukuda S and Saijo Y: Mesenchymal stromal cells promote tumor growth through the enhancement of neovascularization. Mol Med 17: 579-587, 2011.

116. Lu L, Chen G, Yang J, Ma Z, Yang Y, Hu Y, Lu Y, Cao Z, Wang Y and Wang $\mathrm{X}$ : Bone marrow mesenchymal stem cells suppress growth and promote the apoptosis of glioma U251 cells through downregulation of the PI3K/AKT signaling pathway. Biomed Pharmacother 112: 108625, 2019
117. Bajetto A, Pattarozzi A, Corsaro A, Barbieri F, Daga A, Bosio A Gatti M, Pisaturo V, Sirito R and Florio T: Different effects of human umbilical cord mesenchymal stem cells on glioblastoma stem cells by direct cell interaction or via released soluble factors. Front Cell Neurosci 11: 312, 2017.

118. Zheng H, Zou W, Shen J, Xu L, Wang S, Fu YX and Fan W: Opposite effects of coinjection and distant injection of mesenchymal stem cells on breast tumor cell growth. Stem Cells Transl Med 5: 1216-1228, 2016.

119. Akimoto K, Kimura K, Nagano M, Takano S, To'a Salazar G, Yamashita $\mathrm{T}$ and Ohneda O: Umbilical cord blood-derived mesenchymal stem cells inhibit, but adipose tissue-derived mesenchymal stem cells promote, glioblastoma multiforme proliferation. Stem Cells Dev 22: 1370-1386, 2013.

120. Barcellos-de-Souza P, Comito G, Pons-Segura C, Taddei ML, Gori V, Becherucci V, Bambi F, Margheri F, Laurenzana A, Del Rosso $\mathrm{M}$ and Chiarugi P: Mesenchymal stem cells are recruited and activated into carcinoma-associated fibroblasts by prostate cancer microenvironment-derived TGF- $\beta 1$. Stem Cells 34: 2536-2547, 2016.

121. Hill BS, Pelagalli A, Passaro N and Zannetti A: Tumor-educated mesenchymal stem cells promote pro-metastatic phenotype. Oncotarget 8: 73296-73311, 2017.

122. Tan HX, Xiao ZG, Huang T, Fang ZX, Liu Y and Huang ZC: CXCR4/TGF- $\beta 1$ mediated self-differentiation of human mesenchymal stem cells to carcinoma-associated fibroblasts and promoted colorectal carcinoma development. Cancer Biol Ther 21: 248-257, 2020.

123. Walter M, Liang S, Ghosh S, Hornsby PJ and Li R: Interleukin 6 secreted from adipose stromal cells promotes migration and invasion of breast cancer cells. Oncogene 28: 2745-2755, 2009.

124. Tsai KS, Yang SH, Lei YP, Tsai CC, Chen HW, Hsu CY, Chen LL, Wang HW, Miller SA, Chiou SH, et al: Mesenchymal stem cells promote formation of colorectal tumors in mice. Gastroenterology 141: 1046-1056, 2011

125. Zhang T, Lee YW, Rui YF, Cheng TY, Jiang XH and Li G: Bone marrow-derived mesenchymal stem cells promote growth and angiogenesis of breast and prostate tumors. Stem Cell Res Ther 4: 70, 2013.

126. El-Haibi CP, Bell GW, Zhang J, Collmann AY, Wood D Scherber CM, Csizmadia E, Mariani O, Zhu C, Campagne A, et al: Critical role for lysyl oxidase in mesenchymal stem cell-driven breast cancer malignancy. Proc Natl Acad Sci USA 109: 17460-17465, 2012

127. Patel SA, Meyer JR, Greco SJ, Corcoran KE, Bryan M and Rameshwar P: Mesenchymal stem cells protect breast cancer cells through regulatory $\mathrm{T}$ cells: Role of mesenchymal stem cell-derived TGF-beta. J Immunol 184: 5885-5894, 2010.

128. Gazdic M, Markovic BS, Jovicic N, Misirkic-Marjanovic M, Djonov V, Jakovljevic V, Arsenijevic N, Lukic ML and Volarevic V: Mesenchymal stem cells promote metastasis of lung cancer cells by downregulating systemic antitumor immune response. Stem Cells Int 2017: 6294717, 2017.

129. Ramasamy R, Lam EWF, Soeiro I, Tisato V, Bonnet D and Dazzi F: Mesenchymal stem cells inhibit proliferation and apoptosis of tumor cells: Impact on in vivo tumor growth. Leukemia 21: 304-310, 2007.

130. He N, Kong Y, Lei X, Liu Y, Wang J, Xu C, Wang Y, Du L, Ji K, Wang Q, et al: MSCs inhibit tumor progression and enhance radiosensitivity of breast cancer cells by down-regulating Stat3 signaling pathway. Cell Death Dis 9: 1026, 2018.

131. Yulyana Y, Ho IAW, Sia KC, Newman JP, Toh XY, Endaya BB, Chan JKY, Gnecchi M, Huynh H, Chung AY, et al: Paracrine factors of human fetal MSCs inhibit liver cancer growth through reduced activation of IGF-1R/PI3K/Akt signaling. Mol Ther 23: 746-756, 2015

132. Chen HL, Li JJ, Jiang F, Shi WJ and Chang GY: MicroRNA-4461 derived from bone marrow mesenchymal stem cell exosomes inhibits tumorigenesis by downregulating COPB2 expression in colorectal cancer. Biosci Biotechnol Biochem 84: 338-346, 2020.

133. Ho IAW, Toh HC, Ng WH, Teo YL, Guo CM, Hui KM and Lam PYP: Human bone marrow-derived mesenchymal stem cells suppress human glioma growth through inhibition of angiogenesis. Stem Cells 31: 146-155, 2013.

134. Khalil C, Moussa M, Azar A, Tawk J, Habbouche J, Salameh R, Ibrahim A and Alaaeddine N: Anti-proliferative effects of mesenchymal stem cells (MSCs) derived from multiple sources on ovarian cancer cell lines: An in-vitro experimental study. J Ovarian Res 12: 70, 2019. 
135. DiDonato JA, Mercurio F and Karin M: NF- $\kappa \mathrm{B}$ and the link between inflammation and cancer. Immunol Rev 246: 379-400, 2012.

136. Li M, Kouzmina E, McCusker M, Rodin D, Boutros PC, Paige CJ and Rodin G: Pro- and anti-inflammatory cytokine associations with major depression in cancer patients. Psychooncology 26: 2149-2156, 2017.

137. Ahechu P, Zozaya G, Martí P, Hernández-Lizoáin JL, Baixauli J, Unamuno X, Frühbeck G and Catalán V: NLRP3 inflammasome: A possible link between obesity-associated low-grade chronic inflammation and colorectal cancer development. Front Immunol 9: 2918, 2018.

138. Mocellin S, Panelli MC, Wang E, Nagorsen D and Marincola FM: The dual role of IL-10. Trends Immunol 24 36-43, 2003

139. Tanikawa T, Wilke CM, Kryczek I, Chen GY, Kao J, Núñez G and Zou W: Interleukin-10 ablation promotes tumor development, growth, and metastasis. Cancer Res 72: 420-429, 2012.

140. Nappo G, Handle F, Santer FR, McNeill RV, Seed RI, Collins AT, Morrone G, Culig Z, Maitland NJ and Erb HHH The immunosuppressive cytokine interleukin-4 increases the clonogenic potential of prostate stem-like cells by activation of STAT6 signalling. Oncogenesis 6: e342, 2017.

141. Setrerrahmane S and Xu H: Tumor-related iCnterleukins: Old validated targets for new anti-cancer drug development. Mol Cancer 16: 153, 2017.

142. Saeedi P, Halabian R and Fooladi AA: A revealing review of mesenchymal stem cells therapy, clinical perspectives and modification strategies. Stem Cell Investig 6: 34, 2019

143. Bortolotti F, Ukovich L, Razban V, Martinelli V, Ruozi G, Pelos B, Dore F, Giacca M and Zacchigna S: In vivo therapeutic potential of mesenchymal stromal cells depends on the source and the isolation procedure. Stem Cell Rep 4: 332-339, 2015.

144. Fathi E, Sanaat Z and Farahzadi R: Mesenchymal stem cells in acute myeloid leukemia: A focus on mechanisms involved and therapeutic concepts. Blood Res 54: 165-174, 2019.

145. Chen Y, He Y, Wang X, Lu F and Gao J: Adipose-derived mesenchymal stem cells exhibit tumor tropism and promote tumorsphere formation of breast cancer cells. Oncol Rep 41: 2126-2136, 2019.

146. Dührsen L, Hartfuß S, Hirsch D, Geiger S, Maire CL, Sedlacik J, Guenther C, Westphal M, Lamszus K, Hermann FG and Schmidt NO: Preclinical analysis of human mesenchymal stem cells: Tumor tropism and therapeutic efficiency of local HSV-TK suicide gene therapy in glioblastoma. Oncotarget 10: 6049-6061, 2019.

147. Dissanayake S, Denny WA, Gamage S and Sarojini V: Recent developments in anticancer drug delivery using cell penetrating and tumor targeting peptides. J Control Release 250: 62-76, 2017

148. Lagoa R, Silva J, Rodrigues JR and Bishayee A: Advances in phytochemical delivery systems for improved anticancer activity. Biotechnol Adv 38: 107382, 2020.

149. Studeny M, Marini FC, Champlin RE, Zompetta C, Fidler IJ and Andreeff M: Bone marrow-derived mesenchymal stem cells as vehicles for interferon-beta delivery into tumors. Cancer Res 62 : 3603-3608, 2002

150. Ahn JO, Lee HW, Seo KW, Kang SK, Ra JC and Youn HY: Anti-tumor effect of adipose tissue derived-mesenchymal stem cells expressing interferon- $\beta$ and treatment with cisplatin in a xenograft mouse model for canine melanoma. PLoS One 8: e74897, 2013

151. Shen CJ, Chan TF, Chen CC, Hsu YC, Long CY and Lai CS: Human umbilical cord matrix-derived stem cells expressing interferon- $\beta$ gene inhibit breast cancer cells via apoptosis Oncotarget 7: 34172-34179, 2016.

152. Yuan ZQ, Kolluri KK, Sage EK, Gowers KHC and Janes SM: Mesenchymal stromal cell delivery of full-length tumor necrosis factor-related apoptosis-inducing ligand is superior to soluble type for cancer therapy. Cytotherapy 17: 885-896, 2015.

153. Marini I, Siegemund M, Hutt M, Kontermann RE and Pfizenmaier K: Antitumor activity of a mesenchymal stem cell line stably secreting a tumor-targeted TNF-related apoptosis-inducing ligand fusion protein. Front Immunol 8: 536, 2017.

154. Guiho R, Biteau K, Grisendi G, Chatelais M, Brion R, Taurelle J, Renault S, Heymann D, Dominici M and Redini F: In vitro and in vivo discrepancy in inducing apoptosis by mesenchymal stromal cells delivering membrane-bound tumor necrosis factor-related apoptosis inducing ligand in osteosarcoma pre-clinical models. Cytotherapy 20: 1037-1045, 2018.
155. Shamili FH, Bayegi HR, Salmasi Z, Sadri K, Mahmoudi M, Kalantari M, Ramezani M and Abnous K: Exosomes derived from TRAIL-engineered mesenchymal stem cells with effective anti-tumor activity in a mouse melanoma model. Int J Pharm 549: 218-229, 2018.

156. Yang $X, \mathrm{Du} J, \mathrm{Xu} X, \mathrm{Xu} \mathrm{C}$ and Song W: IFN- $\gamma$-secretingmesenchymal stem cells exert an antitumor effect in vivo via the TRAIL pathway. J Immunol Res 2014: e318098, 2014.

157. You Q, Yao Y, Zhang Y, Fu S, Du M and Zhang G: Effect of targeted ovarian cancer therapy using amniotic fluid mesenchymal stem cells transfected with enhanced green fluorescent protein-human interleukin-2 in vivo. Mol Med Rep 12: 4859-4866, 2015

158. Zhao W, Cheng J, Shi P and Huang J: Human umbilical cord mesenchymal stem cells with adenovirus-mediated interleukin 12 gene transduction inhibits the growth of ovarian carcinoma cells both in vitro and in vivo. Nan Fang Yi Ke Da Xue Xue Bao 31: 903-907, 2011 (In Chinese).

159. Zhang X, Zhang L, Xu W, Qian H, Ye S, Zhu W, Cao H, Yan Y, Li W, Wang M, et al: Experimental therapy for lung cancer: Umbilical cord-derived mesenchymal stem cell-mediated interleukin-24 delivery. Curr Cancer Drug Targets 13: 92-102, 2013

160. Nowakowski A, Walczak P, Lukomska B and Janowski M Genetic engineering of mesenchymal stem cells to induce their migration and survival. Stem Cells Int 2016: e4956063, 2016.

161. Wei W, Huang Y, Li D, Gou HF and Wang W: Improved therapeutic potential of MSCs by genetic modification. Gene Ther 25 538-547, 2018

162. Ocansey DKW, Pei B, Yan Y, Qian H, Zhang X, Xu W and Mao F: Improved therapeutics of modified mesenchymal stem cells: An update. J Transl Med 18: 42, 2020

163. Phillips MI and Tang YL: Genetic modification of stem cells for transplantation. Adv Drug Deliv Rev 60: 160-172, 2008.

164. Bobis-Wozowicz S, Miekus K, Wybieralska E, Jarocha D, Zawisz A, Madeja Z and Majka M: Genetically modified adipose tissue-derived mesenchymal stem cells overexpressing CXCR4 display increased motility, invasiveness, and homing to bone marrow of NOD/SCID mice. Exp Hematol 39: 686-696, 2011.

165. Pelagalli A, Nardelli A, Lucarelli E, Zannetti A and Brunetti A: Autocrine signals increase ovine mesenchymal stem cells migration through Aquaporin-1 and CXCR4 overexpression. J Cell Physiol 233: 6241-6249, 2018

166. Song SW, Chang W, Song BW, Song H, Lim S, Kim HJ, Cha MJ, Choi E, Im SH, Chang BC, et al: Integrin-linked kinase is required in hypoxic mesenchymal stem cells for strengthening cell adhesion to ischemic myocardium. Stem Cells 27: 1358-1365, 2009.

167. Fan YX, Gu CH, Zhang YL, Zhong BS, Wang LZ, Zhou ZR, Wang ZY, Jia RX and Wang F: Oct4 and Sox2 overexpression improves the proliferation and differentiation of bone mesenchymal stem cells in Xiaomeishan porcine. Genet Mol Res 12: 6067-6079, 2013

168. Han SM, Han SH, Coh YR, Jang G, Ra JC, Kang SK, Lee HW and Youn HY: Enhanced proliferation and differentiation of Oct4- and Sox2-overexpressing human adipose tissue mesenchymal stem cells. Exp Mol Med 46: e101, 2014.

169. Becker AD and Riet IV: Homing and migration of mesenchymal stromal cells: How to improve the efficacy of cell therapy? World J Stem Cells 8: 73-87, 2016.

170. DelaRosa O, Dalemans W and Lombardo E: Toll-like receptors as modulators of mesenchymal stem cells. Front Immunol 3 : $182,2012$.

171. Najar M, Krayem M, Meuleman N, Bron D and Lagneaux L: Mesenchymal stromal cells and toll-like receptor priming: A critical review. Immune Netw 17: 89-102, 2017.

172. Mekhemar MK, Dörfer CE and El-Sayed KMF: Toll-like receptors: The key of immunotherapy in MSCs. In: Immunoregulatory aspects of immunotherapy. IntechOpen, pp 173, 2018.

173. Waterman RS, Tomchuck SL, Henkle SL and Betancourt AM: A new mesenchymal stem cell (MSC) paradigm: Polarization into a pro-inflammatory MSC1 or an immunosuppressive MSC2 phenotype. PLoS One 5: e10088, 2010

174. Kim J and Hematti P: Mesenchymal stem cell-educated macrophages: A novel type of alternatively activated macrophages. Exp Hematol 37: 1445-1453, 2009

175. Cassatella MA, Mosna F, Micheletti A, Lisi V, Tamassia N, Cont C, Calzetti F, Pelletier M, Pizzolo G and Krampera M: Toll-like receptor-3-activated human mesenchymal stromal cells significantly prolong the survival and function of neutrophils. Stem Cells 29: 1001-1011, 2011 
176. Hall SRR, Tsoyi K, Ith B, Padera RF Jr, Lederer JA, Wang Z, Liu X and Perrella MA: Mesenchymal stromal cells improve survival during sepsis in the absence of heme oxygenase-1: The importance of neutrophils. Stem Cells 31: 397-407. 2013.

177. Jiang W and Xu J: Immune modulation by mesenchymal stem cells Cell Prolif 53: e12712, 2019.

178. Kudlik G, Hegyi B, Czibula Á, Monostori É, Buday L and Uher F: Mesenchymal stem cells promote macrophage polarization toward M2b-like cells. Exp Cell Res 348: 36-45, 2016.

179. Spaggiari GM, Capobianco A, Abdelrazik H, Becchetti F, Mingari MC and Moretta L: Mesenchymal stem cells inhibit natural killer-cell proliferation, cytotoxicity, and cytokine production: Role of indoleamine 2,3-dioxygenase and prostaglandin E2. Blood 111: 1327-1333, 2008.

180. Gonzalez H, Hagerling C and Werb Z: Roles of the immune system in cancer: From tumor initiation to metastatic progression. Genes Dev 32: 1267-1284, 2018.

181. Vinay DS, Ryan EP, Pawelec G, Talib WH, Stagg J, Elkord E, Lichtor T, Decker WK, Whelan RL, Kumara HM, et al: Immune evasion in cancer: Mechanistic basis and therapeutic strategies. Semin Cancer Biol 35 (Suppl): S185-S198, 2015.

182. Du W, Seah I, Bougazzoul O, Choi G, Meeth K, Bosenberg MW, Wakimoto H, Fisher D and Shah K: Stem cell-released oncolytic herpes simplex virus has therapeutic efficacy in brain metastatic melanomas. Proc Natl Acad Sci USA 114: E6157-E6165, 2017.

183. Guo Y, Zhang Z, Xu X, Xu Z, Wang S, Huang D, Li Y, Mou X, Liu F and Xiang C: Menstrual blood-derived stem cells as delivery vehicles for oncolytic adenovirus virotherapy for colorectal cancer. Stem Cells Dev 28: 882-896, 2019.

184. Mahasa KJ, Pillis Ld, Ouifki R, Eladdadi A, Maini P, Yoon AR and Yun CO: Mesenchymal stem cells used as carrier cells of oncolytic adenovirus results in enhanced oncolytic virotherapy. Sci Rep 10: 425, 2020.

185. Pessina A, Coccè V, Pascucci L, Bonomi A, Cavicchini L, Sisto F, Ferrari M, Ciusani E, Crovace A, Falchetti ML, et al: Mesenchymal stromal cells primed with paclitaxel attract and kill leukaemia cells, inhibit angiogenesis and improve survival of leukaemia-bearing mice. Br J Haematol 160: 766-778, 2013.

186. Gilazieva Z, Tazetdinova L, Arkhipova S, Solovyeva V and Rizvanov A: Effect of cisplatin on ultrastructure and viability of adipose-derived mesenchymal stem cells. BioNanoScience 6 : 534-539, 2016

187. Nicolay NH, Perez RL, Rühle A, Trinh T, Sisombath S, Weber KJ, Ho AD, Debus J, Saffrich R and Huber PE: Mesenchymal stem cells maintain their defining stem cell characteristics after treatment with cisplatin. Sci Rep 6: 20035, 2016.

188. Pascucci L, Coccè V, Bonomi A, Ami D, Ceccarelli P, Ciusani E, Viganò L, Locatelli A, Sisto F, Doglia SM, et al: Paclitaxel is incorporated by mesenchymal stromal cells and released in exosomes that inhibit in vitro tumor growth: A new approach for drug delivery. J Control Release 192: 262-270, 2014.

189. Pessina A, Bonomi A, Coccè V, Invernici G, Navone S, Cavicchini L, Sisto F, Ferrari M, Viganò L, Locatelli A, et al: Mesenchymal stromal cells primed with paclitaxel provide a new approach for cancer therapy. PLoS One 6: e28321, 2011

190. Bonomi A, Coccè V, Cavicchini L, Sisto F, Dossena M Balzarini P, Portolani N, Ciusani E, Parati E, Alessandri G and Pessina A: Adipose tissue-derived stromal cells primed in vitro with paclitaxel acquire anti-tumor activity. Int J Immunopathol Pharmacol 26 (Suppl 1): S33-S41, 2013.

191. Coccè V, Franzè S, Brini AT, Giannì AB, Pascucci L, Ciusani E, Alessandri G, Farronato G, Cavicchini L, Sordi V, et al: In vitro anticancer activity of extracellular vesicles (EVs) secreted by gingival mesenchymal stromal cells primed with paclitaxel. Pharmaceutics 11: 61, 2019.

192. Coccè V, Farronato D, Brini AT, Masia C, Giannì AB, Piovani G, Sisto F, Alessandri G, Angiero F and Pessina A: Drug loaded gingival mesenchymal stromal cells (GinPa-MSCs) inhibit in vitro proliferation of oral squamous cell carcinoma. Sci Rep 7: 9376, 2017.
193. Layek B, Sadhukha T, Panyam J and Prabha S: Nano-engineered mesenchymal stem cells increase therapeutic efficacy of anticancer drug through true active tumor targeting. Mol Cancer Ther 17: 1196-1206, 2018.

194. Moku G, Layek B, Trautman L, Putnam S, Panyam J and Prabha S: Improving payload capacity and anti-tumor efficacy of mesenchymal stem cells using TAT peptide functionalized polymeric nanoparticles. Cancers (Basel) 11: 491, 2019.

195. Altun İ and Sonkaya A: The most common side effects experienced by patients were receiving first cycle of chemotherapy. Iran J Public Health 47: 1218-1219, 2018.

196. Kim W, Lee SK, Kwon YW, Chung SG and Kim S: Pioglitazone-primed mesenchymal stem cells stimulate cell proliferation, collagen synthesis and matrix gene expression in tenocytes. Int J Mol Sci 20: 472, 2019.

197. Hong Y, Kim YS, Hong SH and Oh YM: Therapeutic effects of adipose-derived stem cells pretreated with pioglitazone in an emphysema mouse model. Exp Mol Med 48: e266, 2016.

198. Park JS, Kim HK, Kang EY, Cho R and Oh YM: Potential therapeutic strategy in chronic obstructive pulmonary disease using pioglitazone-augmented Wharton's jelly-derived mesenchymal stem cells. Tuberc Respir Dis (Seoul) 82: 158-165, 2019.

199. Khoo BY, Nadarajan K, Shim SY, Miswan N, Zang CB, Possinger K and Elstner E: Pretreatment of BMSCs with TZD solution decreases the proliferation rate of MCF-7 cells by reducing FGF4 protein expression. Mol Med Rep 13: 3406-3414, 2016.

200. Tsubaki M, Takeda T, Tomonari Y, Kawashima K, Itoh T, Imano M, Satou T and Nishida S: Pioglitazone inhibits cancer cell growth through STAT3 inhibition and enhanced AIF expression via a PPAR $\gamma$-independent pathway. J Cell Physiol 233: 3638-3647, 2018.

201. Moghareabed R, Hemati S, Akhavan A, Emami H, Farghadani M, Roayaei M, Tavajoh S and Feizi A: Randomized phase II clinical trial of pioglitazone plus chemotherapy versus chemotherapy alone in patients with metastatic breast cancer. J Glob Oncol 5: 83, 2019.

202.Esmaeili S, Safaroghli-Azar A, Pourbagheri-Sigaroodi A, Salari S, Gharehbaghian A, Hamidpour M and Bashash D: Activation of PPAR $\gamma$ intensified the effects of arsenic trioxide in acute promyelocytic leukemia through the suppression of PI3K/Akt pathway: Proposing a novel anticancer effect for pioglitazone. Int J Biochem Cell Biol 122 105739,2020

203. Shinmura D, Togashi I, Miyoshi S, Nishiyama N, Hida N, Tsuji H, Tsuruta H, Segawa K, Tsukada Y, Ogawa S and Umezawa A: Pretreatment of human mesenchymal stem cells with pioglitazone improved efficiency of cardiomyogenic transdifferentiation and cardiac function. Stem Cells 29: 357-366, 2011.

204. Wang M, Cai J, Huang F, Zhu M, Zhang Q, Yang T, Zhang X, Qian $\mathrm{H}$ and $\mathrm{Xu} \mathrm{W}$ : Pre-treatment of human umbilical cord-derived mesenchymal stem cells with interleukin-6 abolishes their growth-promoting effect on gastric cancer cells. Int J Mol Med 35: 367-375, 2015.

205. von Bahr L, Sundberg B, Lönnies L, Sander B, Karbach H, Hägglund H, Ljungman P, Gustafsson B, Karlsson H, Blanc KL and Ringdén O: Long-term complications, immunologic effects, and role of passage for outcome in mesenchymal stromal cell therapy. Biol Blood Marrow Transplant 18: 557-564, 2012.

c) (i) $\ominus$ This work is licensed under a Creative Commons Attribution-NonCommercial-NoDerivatives 4.0 International (CC BY-NC-ND 4.0) License. 